\title{
LA TUTELA JURÍDICA DEL AGUA EN EL DERECHO ROMANO*
}

\author{
LEGAL PROTECTION OF WATER IN ROMAN LAW \\ Juan David Terrazas Ponce ${ }^{* *}$
}

\begin{abstract}
RESUMEN: El presente artículo tiene como finalidad analizar la regulación jurídica de las aguas en el Derecho Romano, desde una mirada, basada en la genuina mentalidad de los juristas, que más preocupados de la solución justa al caso concreto, dejan como un elemento secundario la fatigosa tarea de clasificación del agua dentro de las diversas categorías de cosa.

Palabras clave: Agua, Interdictos, Flumina-Rivi.

ABSTRACT: The purpose of this paper is to analyze the law of water under Roman law, explaining the views of Roman legal scholars on this subject. It shall show that they were primary concerned in obtaining just solutions to concrete cases and not worried on how to classify water within the various definitions of things.
\end{abstract}

Key words: Water, Interdicts, Flumina-Rivi.

\section{INTRODUCCIÓN}

Una vez estudiado el régimen jurídico de las aguas en el Derecho Romano, no podemos menos que estar de acuerdo con la opinión de D'ORs', en orden a que "el agua, aunque se halle en una finca privada, no es objeto de propiedad; su consumo es común, sin perjuicio del ius prohibendi del propietario de la finca para impedir la entrada en ella sin su permiso". En efecto, para llegar a esta conclusión general, basta solo realizar un pequeño repaso respecto de la tutela jurídica a la que está sometida el agua y lo primero que resalta en este análisis es que desde el punto de vista técnico, esto es la posibilidad de que una cosa sea reivindicada, ella no es "res" dado que sus características inherentes impiden diferenciar una cantidad de agua de otra. Prueba de ello es que no hay pasajes en las fuentes que se refieran, aun de manera indirecta al ejercicio de la reivindicatio para estos casos e incluso no es objeto de posesión civil y ni aun pretoria, pues la hipótesis cubierta por el interdicto

\footnotetext{
* El presente trabajo, corresponde a la primera parte del Capítulo III de nuestra tesis doctoral, "RÉGIMEN Jurídico de las aguas en el Derecho Romano", desarrollada en el Programa de Doctorado de la Facultad de Derecho de la Pontificia Universidad Católica de Chile, dirigida por el Dr. Francisco Samper Polo y aprobada con máxima distinción (cum laude) por un tribunal presidido por el Dr. Alejandro Guzmán Brito. En diciembre de 2010, dicha tesis obtuvo el "Premio a la Excelencia en Tesis Doctoral 2010", otorgado por la Vicerrectoría de Investigación de la Pontificia Universidad Católica de Chile.

${ }^{*}$ Profesor de Derecho Romano, Universidad Andrés Bello. Correo electrónico: jterrazas@unab.cl. Licenciado en Derecho, Pontificia Universidad Católica de Chile. Magíster en Ciencia Jurídica y Doctor en Derecho, Pontificia Universidad Católica de Chile.
}

${ }^{1}$ D'Ors (2004) p. 180. 
uti possidetis se refiere a la protección del fundo donde escurre el curso de agua y no a dicho curso como tal.

En definitiva, si nos remitimos exclusivamente a los recursos que se relacionan directamente con el agua, nos encontramos con que estos son: la actio aquae pluviae arcendae, las acciones vinculadas a la servidumbre (vindicatio y negatoria servitutis) y especialmente algunos interdictos. Ahora, si precisamos la finalidad seguida por cada uno de ellos, la verdad es que nos encontramos con un cuadro en que el objeto de la tutela no es el agua, sino la protección de un fundo respecto de eventuales daños o immissiones y el uso, admitido para todos, del recurso natural. El punto resalta aun más si traemos a colación el hecho de que en el caso del daño provocado al agua (contaminación, por ejemplo), no procede la actio legis Aquiliae, sino el interdicto quod vi aut clam. De todo lo anterior podemos concluir que el concepto que más se acerca al pensamiento de los juristas es que cualquiera se puede aprovechar del agua, mientras este provecho no perjudique a otros, afecte una servidumbre o signifique el ejercicio de hecho de una de ellas que en realidad no existe.

Decíamos que la tutela del agua se hace a través de interdictos y al respecto conviene en este punto recordar, tal como lo hace GUZMán BRITO², que en el derecho clásico existe una nítida diferenciación entre actio e interdictum, la que con posterioridad evoluciona al punto de que en el periodo justinianeo la diversidad recién apuntada se pierde. Pese a esta realidad, las noticias que nos llegan a través de las fuentes permiten esbozar la idea del interdictum clásico, en cuanto este tiene por contenido una orden que el magistrado dirige a una o varias personas en el sentido de imponer un determinado comportamiento de las mismas, teniendo muy claro que “...aunque suponga una contienda entre las partes, la solicitud de una de ellas al magistrado (pretor o gobernador), y un somero conocimiento de los hechos por parte del que lo emite, un interdictum no decide la controversia en concreto, ni la reenvía a un juez, sino que la decide unilateralmente en abstracto. El interdicto contiene una hipótesis de hecho y un mandato o prohibición del magistrado, dirigida a una de las partes o a ambas, pero que vale en cuanto su o sus destinatarios efectivamente se encuentren en dicha hipótesis" 3 . En consecuencia y dada su naturaleza el interdictum no da lugar a un examen de la controversia jurídica entre las partes, sino simplemente a la tutela del estado actual de las cosas, particularmente por el hecho de que su existencia siempre se encuentra vinculada de algún modo al interés común ${ }^{4}$.

La fuente del interdicto se encuentra en el edicto del pretor, pero a diferencia de lo que podría suponerse no existe una fórmula única que permita ser amoldada a diferentes circunstancias, sino una multiplicidad de interdictos que obedecen a otras tantas situaciones de hecho que se encuentran tuteladas 5 . Como lo que a nosotros nos interesa se re-

\footnotetext{
${ }^{2}$ GuZMán Brito (1996) T.I, pp. 192 ss.

${ }^{3}$ GuZMán Brito (1996) T. I, p. 193.

${ }^{4}$ GAYo, realiza una clasificación que permite distinguir entre interdictos "simples" y "dobles", aunque no es la única, pues es común también clasificarlos de acuerdo al contenido de la orden en "prohibitorios"; "restitutorios" y "exhibitorios". Vid., Gai. 4, 142; 4, 156.

5 Pese a esto, se puede presentar el caso en que el magistrado conceda el interdicto aun cuando la situación de hecho no sea exactamente la que sirve de supuesto para su concesión, caso en el que se dice de aquel un "interdictum utile".
} 
laciona directamente con el régimen de las aguas, solo centraremos nuestro análisis en los siguientes: "interdictum ne quid in flumine publico eius flat, quod peius navigetur"; "interdictum ne quid in flumine publico ripave eius fiat, quod aliter aqua fluat"7; interdictum ut in fumine publico navigare liceat" $\mathrm{y}$; "interdictum de ripa munienda"9.

\section{II. "FLUMINA";"RIVI"}

Sin perjuicio de que, como decíamos, el centro de esta exposición está en los interdictos que ya hemos enunciado, existe un asunto preliminar que debemos enfrentar: se trata de establecer el contenido de dos conceptos esenciales y que sirven de base a todo el discurso posterior que proponemos: ellos son los de "flumina" y "rivi", pues estos sirven para contextualizar el desarrollo reflejado en el régimen interdictal que tiende a impedir aquellos actos que afecten los cursos de agua y que pueden ocasionar perjuicios a terceros ${ }^{10}$. Finalmente esto se traduce en que a cada uno de los tipos de turbación corresponde un medio específico de tutela, situación que además es mediatizada con los aportes derivados de la labor de los juristas, quienes trabajan intensamente en verificar los presupuestos y límites del ejercicio de los interdictos, explorando la posibilidad de extenderlos hacia hipótesis originalmente no consideradas ${ }^{11}$.

Así el primer interdicto que es tratado en el Digesto y que se refiere a las materias propias de este artículo es el "ne quid in flumine publico ripave eius fiat, quo peius navigetur" 12 , y luego de fijar el texto del mismo, tema sobre el que tendremos más adelante oportunidad de detenernos, prosigue con la clasificación entre "flumina" y "rivi"; para pasar a aquella que diferencia entre "flumina perennia" y "torrentia" y; finalmente terminar con la distinción entre "flumina publica" y "flumina privata".

Así, la base textual, que sirve de punto de partida del análisis que llevaremos a continuación está constituida por el siguiente texto:

D. 43, 12, 1, 1-3 (Ulp. 68 ad ed.)

Flumen a rivo magnitudine discernendum esta ut existimatione circumcolentium. (2) Item fluminum quaedam sunt perennia, quaedam torrentia. Perenne est, quod semper

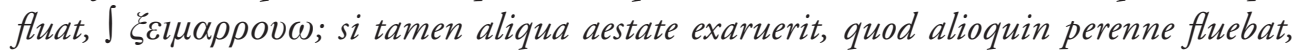
non ideo minus perenne est. (3) Fluminum quaedam publica sunt, quaedam non. Publicum flumen esse Cassius definit, quo d perenne sit: haec sententia Cassii, quam et Celsus probat, videtur esse probabilis.

\footnotetext{
${ }^{6}$ D. 43,$12 ; E P .43,241$.

${ }^{7}$ D. 43,$13 ; E P .43,242$.

${ }^{8}$ D. 43,$14 ; E P .43,243$.

${ }^{9}$ D. 43,$15 ; E P .43,244$.

${ }^{10}$ GLÜCK (1906) XLIII-XLIV, p. 466.

${ }^{11}$ Rodger (1989) pp. 177 ss.

${ }^{12}$ D. 13, 12, 1 pr. (Ulp. 68 ad. ed.).
} 
A partir del estudio de este pasaje se han tratado de establecer una serie de teorías que intentan determinar cuáles habrían sido los caracteres que permitirían calificar un curso de agua como "público"13. Sin embargo, en ellas se produce una imprecisión terminológica y conceptual notable, que no hacen más que distorsionar la discusión, pues llevan a generar confusión en el criterio básico con que miraban el asunto los juristas romanos: no se trata de establecer si el agua que escurre por dichos cursos es pública o privada, sino que dicha definición recae sobre el curso mismo, por lo que finalmente no se puede presentar el esquema en términos de una contradicción en el binomio aqua publica-aqua privata ${ }^{14}$; sino en el constituido por cursos de agua privados y cursos de agua públicos ${ }^{15}$. Todavía hay algunos que sostienen que esta distinción en realidad no habría existido ${ }^{16}$, dado que todos los cursos de agua tendrían un elemento común que impide la clasificación y que dice relación con la perennidad de las aguas, lo que además conlleva a que pueda decirse de todos ellos que son "públicos"17. Tras esta doctrina subyace una cuestión importante, ya que propone vincular la expresión "rivi" exclusivamente a cursos de agua artificiales. Sin embargo, aceptar esta tesis, supone pasar por alto la evidencia textual, que precisamente diferencia entre "flumina" y "rivi", sin tener fuentes en qué apoyarse para ello; y aun dejando de lado esta apreciación general, podemos decir que el contenido de D. 43, 12, 1, 1 (Ulp. 68 ad ed.), lejos de prestarse para justificar la irrelevancia de los rivi en el pensamiento de los juristas demuestra lo contrario, dado que si bien es cierto que el interdicto protege la navegabilidad en los flumina publica, cuando posteriormente en D. 42, 12, 1, 12 (Ulp. 68 ad ed.), excluye los cursos no navegables, no los designa como "rivi", sino que utiliza la expresión "flumen".

Resuelto este punto, el pasaje al que hemos hecho referencia distingue muy claramente las siguientes clases de cursos de agua: flumina perennia; fumina torrentia y; rivi.

A propósito de esta problemática, debemos traer a colación dos fragmentos, uno de ellos tomado de las Institutas de Marciano ${ }^{18}$ y el otro incorporado en las propias Institutas de Justiniano ${ }^{19}$, entre las que se puede apreciar un cierto grado de contradicción ${ }^{20}$, que

\footnotetext{
${ }^{13}$ Brugi (1894) pp. 303 ss.

${ }^{14}$ Vid., Astuti (1958) T. 1, p. 350.

15 Desde esta perspectiva es claramente descartable la tesis de Unterholzner (1840) pp. 160 ss., quien sostiene que el criterio de diferenciación estaría marcado por la titularidad del dominio del predio por el que pasa el río: si este es de propiedad estatal, el río es público, de no ser así es privado. Otro tanto puede decirse de la hipótesis esbozada por Plescia (1993) pp. 433 ss., autor que teoriza en torno a una diferenciación in mente de los juristas, nunca expresada, pero siempre presente: hay ríos “internacionales" pues atraviesan varios estados y otros "nacionales", que escurren solo dentro del estado romano. Los primeros son res communes omnium y los segundos podrían ser clasificados como públicos o privados, dependiendo entre otros factores de la titularidad del dominio del predio por el cual escurre. Ambas teorías son rechazadas, pues tal como señala Fiorentini simplemente lo que hacen es aplicar categorías modernas absolutamente ignoradas por los juristas romanos. Vid., Fiorentini (2003) p. 71.

16 Gerez Kraemer (2008) pp. 129 ss.

17 Karadge Iskrow (1928) pp. 50 ss.

18 D. 1, 8, 4, 1 (Marcian. 3 inst.).

${ }^{19}$ Inst. 2, 1, 2.

${ }^{20}$ Todavía más, debe recordarse que existen elementos para afirmar que ambos fragmentos derivarían de un mismo autor: Marciano. Vid., Gerez Kraemer (2008) p. 208.
} 
se materializa en la ausencia de la palabra "paene" 21 en el texto del Digesto. Frente a dicha contradicción la doctrina ha teorizado en torno a la presencia de un glosema o interpolación; o bien, respecto de un olvido involuntario por parte de los compiladores, siendo BRANCA $^{22}$ el único que ha buscado respuestas en una conjetura novedosa que explica la divergencia entre ambos textos en el resultado del intento de los bizantinos por asimilar las res publicae a las res communes omnium, como el objetivo de lograr la homogenización del régimen aplicable a las dos categorías de $\operatorname{cosas}^{23}$. Para pronunciarnos sobre alguna de estas teorías, resulta interesante volver nuestra mirada a las fuentes y fijar el contexto en el que Marciano desarrolla su labor, particularmente en el sentido de que hacia la época en que vivió, la distinción entre flumina publica y privata parece ya asentada ${ }^{24}$, lo que permite hipotizar en torno a que el fragmento recogido en el Digesto es el que más fielmente representa su pensamiento ${ }^{25}$.

Continuando con el estudio del texto que sirve de cabeza para este apartado, en él declara Ulpiano que los criterios para diferenciar flumen de rivus son dos: uno de ellos es objetivo y coincide con las dimensiones del curso de agua en cuestión (flumen si es de una magnitud importante, rivus si no lo es); el otro es subjetivo y tiene relación con la opinión de aquellos que viven en las cercanías de dicho curso de agua. Pero el contenido del pasaje referido en el sentido recién indicado, no se encuentra necesariamente en línea con otros testimonios de que disponemos y de lo que podría resultar una confusión ${ }^{26}$. Por lo mismo, resulta oportuno analizar por separado tanto las fuentes extrajurídicas como las fuentes jurídicas que nos pueden ayudar a solucionar esta problemática, camino que en cierta forma ya ha trazado Fiorentini ${ }^{27}$.

\section{Fuentes eXTRAJURÍdicAs}

Nuestro primer acercamiento al concepto de "flumen" y de "rivus" se centrará en el análisis de algunas fuentes extrajurídicas, que si bien no necesariamente nos dan a conocer el significado técnico de las expresiones, al menos nos permiten tener una idea del uso común u ordinario de los mismos ${ }^{28}$. Nuestro primer aporte, proviene de FEsTo ${ }^{29}$, quien define el concepto de "torrens", centrándolo en la noción de "fluvius" y no de "flumen": puestas así las cosas, "torrens" es un "fluvius subitis imbribus conciatus". Por su parte la "volgi con-

\footnotetext{
${ }^{21}$ Vasalli, F. E. (1939) V. II, pp. 9 ss.

22 Branca (1941) p. 73.

23 Pese a que como decíamos la falta de concordancia entre ambos pasajes se explica por las vías ya enunciadas, no podemos dejar pasar que quien pareciera más preocupado del asunto es Donello (1840), Lib. IV, Cap. III; jurista que afirma la existencia de dos tipos de flumina, públicos y privados, así como la aceptación del criterio de la perennidad para la categorización en el primero de los grupos enunciados.

${ }^{24}$ D. 43, 12, 1, 3-4 (Ulp. 68 ad ed.); D. 39, 3, 1, 23 (Ulp. 53 ad ed.); D. 39, 3, 2 ,9 (Paul. 49 ad ed.); lex Ursonensis.

${ }^{25}$ El fragmento está contenido en la rúbrica "de divisione rerum et qualitate".

26 Por ejemplo, aquella que tiende a confundir "rivus" con "flumen privatus".

27 Fiorentini (2003) pp. 101 ss.

${ }^{28}$ A las fuentes que se revisarán a continuación se puede agregar: Front., De contr. agr., 51, 3 ss.; Sic. FLACC., De cong. agr., 157, 18 ss.

${ }^{29}$ Fest., v. torrens, $484 \mathrm{~L}$.
} 
suetudo", mencionada al final del pasaje, indica la diferencia que se puede establecer entre la expresión "fluvius", que designa el agua en sí misma; y "flumen" que se refiere a la masa hídrica, la corriente o curso de agua. En suma, podemos decir que las conclusiones para la utilización de la terminología descrita son las siguientes: (a) la palabra "flumen" hace una clara referencia a un masa hídrica en movimiento; (b) el término "torrens" indica un fluvius que tiene una inesperada crecida, y; (c) en el concepto de la denominada "volgi consuetudo", flumen comprende cursos de agua perennes y aquellos que pueden ser considerados torrentosos.

En realidad ninguna de estas aproximaciones lingüísticas dan razón de alguna vinculación, aun cuando sea modesta al binomio público-privado que es lo que veremos con posterioridad, termina por interesar a los juristas. Sin embargo, no debemos adelantar conclusiones, pues Ellio Gallo nos permite conocer, como antes anotábamos el sentido ordinario de la expresión hacia el siglo II a. C., lo que ha motivado a Fiorentini ${ }^{30}$ a creer que en este pasaje nuestro autor ha reproducido el sentido "vulgar" de la palabra que tiene un contenido bastante más amplio que el técnico, pues incluye todo tipo de "fluvius", tenga el carácter de perenne o no. Pese a esta crítica, el pasaje finalmente nos permite una precisión: la expresión "flumen" se utiliza para designar específicamente una corriente de agua.

Avanzando, casi un siglo nos encontramos ahora con el testimonio de VARrón ${ }^{31}$, quien relaciona el término "flumen" con el agua que fluye continuamente, esta vez de manera horizontal, puesto en contraposición con el caso del estilicidio que lo hace verticalmente y no de manera continua ${ }^{32}$.

Dejemos de lado por un momento la definitio de "flumen" y pasemos a lo que nos dicen este tipo de fuentes a propósito del "rivus". Iniciaremos el discurso con FesTo ${ }^{33}$, autor que nos da a conocer dos conceptos distintos, que nos permiten aumentar nuestro caudal argumentativo: (a) un sentido "vulgar" que identifica con la expresión los cursos de agua naturales y abiertos; (b) un sentido "técnico" que designa los canales artificiales que aseguran la irrigación o el escurrimiento del agua. Otro tanto nos aporta Hyginio ${ }^{34}$, del que podemos concluir que tanto los rivi como los flumina son regularmente utilizados como límites de predios y en ello tienden al acercamiento en una misma categoría, pero el concepto de rivi incluye dos situaciones que permiten diferenciarlo claramente de los $f(u$ mina: las dimensiones siempre modestas de estos cursos de agua y el hecho de que pueden existir rivi naturales o artificiales, lo que no es factible en el caso de los flumina. Mantengamos esta conclusión preliminar para enfrentar el siguiente apartado.

\section{Fuentes JuRÍdicAs}

Ya hemos advertido que para nosotros resulta esencial el testimonio contenido en D. $43,12,1,1-3$ (Ulp. 68 ad ed.) y no solo por el hecho de que aquí aparecen las definiciones

\footnotetext{
${ }^{30}$ Fiorentini (2003) pp. 79 ss.

${ }^{31}$ VARr., l. lat., 5, 27.

${ }^{32}$ Grosso (1969) pp. 50 y 135.

${ }^{33}$ Fest., v. rivus, 336 L.

${ }^{34}$ Higrn., cond. agr., 74, 10-15 Th.
} 
de términos que hemos venido repitiendo, sino porque incluye aportes de diversos juristas: la contribución de Cassio, la valoración de Ulpiano y la aprobación de Celso.

Indudablemente, hay un elemento que llama inmediatamente la atención y que no estaba incluido en el análisis de las fuentes extrajurídicas: la determinación de si un curso de agua es público o no y el carácter esencial que tiene esta definición en el pasaje que nos transmite Ulpiano. Nos resulta particularmente llamativo que en general la romanística no se detenga demasiado en este aspecto para determinar el verdadero alcance del fragmento, pues como advertiremos dicha circunstancia resultará relevante al momento de comprender adecuadamente el texto ulpianeo. Pero avancemos ordenadamente: una primera clasificación a la que nos enfrenta el texto es la que distingue entre flumen y rivus y al respecto es pertinente reiterar que el texto señala que existen dos criterios para proceder a esta diferenciación: las dimensiones del curso de agua en cuestión (criterio objetivo) y la opinión de aquellos que viven en la cercanía del curso de agua (criterio subjetivo) ${ }^{35}$. De una simple comparación con lo analizado en las fuentes extrajurídicas, se aprecia un resultado inequívoco: los criterios para la calificación no son coincidentes. En efecto, mientras en el pasaje de Festo, observamos una restricción de la noción de "flumen", solo a los fluvius perennis, excluyendo los torrentes; CAssio por el contrario incluye estos últimos dentro de la categoría de flumen, pero indicando que se trata de cursos privados. Entonces, en la dinámica del pasaje ulpianeo que estamos comentando, los torrentes son flumina, pero dada su irregularidad en cuanto a su cauce, son excluidos de la categoría de públicos. Pese a todo y a diferencia de lo que podría pensarse, los fumina privata no son definidos ni caracterizados de forma alguna, sino que simplemente se indica que a ellos no se les aplica el interdicto de que da cuenta el Título 12 del Libro XLIII del Digesto, sirviendo como fundamento para esto lo expresado en el $\$ 4$ en el sentido de que un río privado no difiere en nada de otro lugar privado y por lo mismo, no requiere de tutela especial. Lo dicho ha dado lugar a dos vías de interpretación: una, que podemos encontrar en el pensamiento de Scialoja ${ }^{36}$, supone una antítesis perfecta entre los ríos propiamente dichos y los torrentes, por lo que solo pueden ser catalogados como río público aquel que al mismo tiempo es perenne. La segunda línea de pensamiento representada por $\operatorname{Costa}^{37}$, supone que cuando Ulpiano alude a la perennidad solo lo está haciendo en el sentido de referirse a una condición que puede o no estar, pero que en el primer caso, permite calificar como público el curso de agua en cuestión.

Para resolver adecuadamente el asunto se debe analizar más detenidamente el fragmento, que toma la definición de CAssio $^{38}$ y el parecer de Celso, pues como el mismo

\footnotetext{
35 Alguna parte de la romanística ha restado importancia a este último criterio considerado por el fragmento en análisis. Vid., Ossig (1898) pp. 5 ss.; Plescia (1993) p. 440. Nosotros, siguiendo el criterio de Longo (1966) p. 250, pensamos que no puede quitársele importancia dado el frecuente reconocimiento de los juristas a la realidad práctica.

36 Scialoja (1928) Vol. I, p. 214.

37 Costa (1918) pp. 75 ss.

38 Se trata de un importante jurista que desarrolló su actividad en el siglo I d. C. y que fue discípulo de Sabino. De su obra conocemos la existencia de un tratado de ius civile, distribuida en, a lo menos diez libros. Desafortunadamente, del resto de sus escritos solo tenemos menciones indirectas a través de citas de las cuales desconocemos su origen y en este contexto se encuentran aquellas que se refieren a las aguas: D. $7,8,12,1$
} 
texto nos indica la perennidad como criterio de clasificación de los fumina, no es propia de Ulpiano: sin lugar a dudas hacia finales del siglo I d. C. la definición cassiana debió tener una aceptación relativa, la que se vio impulsada fuertemente con la aprobación de CELSO ${ }^{39}$, aunque desconocemos cuáles fueron las razones para que aceptara un criterio propio de la escuela sabiniana. Indudablemente que la convergencia de criterio de los juristas, lleva a UlPiANO a pronunciarse favorablemente en torno a la opinión de CAssio, pero la cautela de la adhesión permite conjeturar que hacia la época severiana todavía esta opinión no era pacífica $^{40}$. Precisamente la auctoritas de CAssio y Celso, resulta decidora para definir el esquema que asume Ulpiano: el $\$ 1$ distingue entre flumen y rivus; el $\$ 2$ diferencia entre diversos tipos de flumen (perenne, que es aquel que fluye continuamente; y torrens, que es aquel que tiene un flujo discontinuo), y; finalmente el $\$ 3$, que identifica los flumen perennes con los públicos, lo que lleva a concluir que los torrentosos están excluidos de dicho régimen ${ }^{41}$.

Reforzando nuestra idea de las dudas presentadas por Ulpiano, traemos a colación otro argumento: pareciera ser que la elección de los juristas incorporados en el fragmento que estamos comentando no se hizo al azar: Cassio del siglo I, Celso del siglo II; Ulpiano del siglo III. Es sugerente esta secuencia, pues tal vez con ella los compiladores quisieron reforzar la idea de una communis opinio que en realidad solo se logró con posterioridad y de ello daría cuenta PAulo ${ }^{42}$ al seguir el principio enunciado, extendiendo la condición jurídica de los ríos a las orillas de los mismos. En todo caso esta afirmación no debe sorprender, pues cuando las fuentes refieren el término "flumen", lo hacen para designar un curso de agua natural y de alimentación continua en su cauce ${ }^{43}$; sin importar demasiado la entidad del mismo, lo que provocaría en una primera instancia cierta controversia con la opinión del mismo Ulpiano, que ve en aquel aspecto un criterio diferenciador. Sin embargo, no debemos olvidar que también se presenta un segundo criterio, que ya no es geográfico ni físico y que supone la consideración de la opinio circumconlentium.

La estructura de D. 43, 12, 1, 2-3 (Ulp. 68 ad ed.) entonces, debe entenderse inmersa en el contexto del tipo de análisis de las instituciones que realizan los juristas y que

(Ulp. 17 ad Sab.); D. 12, 7, 2 (Ulp. 32 ad ed.); D. 17, 2, 52, 12 (Ulp. 31 ad ed.); D. 33, 7, 12, 16-17 (Ulp. 20 ad Sab.); D. 39, 3, 1, 10-11 (Ulp. 53 ad ed.); D. 39, 3, 1, 19 (Ulp. 53 ad ed.); D. 39, 3, 2, 3 (Paul. 49 ad ed.); D. 39, 3, 11, 1 (Paul. 49 ad ed.); D. 43, 12, 1, 3 (Ulp. 68 ad ed.). Como se puede apreciar fácilmente, UlPIANO parece sentir cierta debilidad por los criterios de CAssio a propósito del régimen de las aguas, pues de todos los fragmentos referidos previamente y donde aparece mencionado este jurista, en una gran mayoría (salvo dos) son tomados de obras de Ulpiano.

${ }^{39}$ Jurista que vivió en el siglo II d. C. A diferencia de lo que ocurre con CAssio, conocemos bastante de su obra, pero a su vez los fragmentos que nos dan a conocer su criterio en orden al régimen de las aguas son más bien escasos: D. 8, 1, 9 (Cel. 5 dig.); D. 8,6,12 (Cel. 23 dig.); D. 19, 1, 38, 2 (Cel. 8 dig.); D. 39, 3, 6, 7 (Ulp. 53 ad ed.); D. 41, 1, 30, 1 (Ulp. 34 ad Sab.); D. 43, 12, 1, 3 (Ulp. 68 ad ed.).

${ }^{40}$ Fiorentini (2003) pp. 90 ss. En contra, Vid., Gerez Kraemer (2008) pp. 182 ss.

${ }^{41}$ Alburquerque (2002) pp. 221 ss.

42 D. 43,12,3 pr. (Paul. 16 ad Sab.).

43 Solo a modo ejemplar podemos citar los siguientes pasajes: D. 39, 2, 9, 1 (Ulp. 53 ad ed.); D. 39, 2, 24, 5 (Ulp. 81 ad ed.); D. 41, 1, 7, 1-5 (Gai. 2 rer. cott.); D. 41, 1, 15 (Nerat. 5 reg.); D. 41, 1, 38 (Alf. 4 dig. a Paul. epit.); D. 41, 1, 56 pr.-1 (Proc. 8 epist.); D. 41, 1, 65, 1-4 (Lab. 6 pith. a Paul. epit.); D. 41, 2, 3, 17 (Paul. 54 ad ed.); D. 44, 2, 26, 1 (Afric. 9 quaest.). 
es muy diferente al que resulta normal para la dogmática moderna, la que no entiende una explicación como tal si primero no se define aquello que se pretende dar a entender. Al contrario los juristas romanos comienzan muchas veces sus explicaciones con diferenciaciones de género, para luego distinguir especies y finalmente presentar una definición ${ }^{44}$ : nuestro pasaje sigue ese derrotero, dado que se parte de un género básico que sería el "aqua currens" 45 y a partir de ahí se distingue entre fumina y rivi, para luego diferenciar en los primeros entre públicos y privados. Solo en este punto aparece la definición de flumen público, por lo que la contraposición flumina perennia-flumina torrentia, solo es útil para fijar el concepto de flumen publicum e incluso en este sentido es absolutamente utilitaria y no esencial.

A la luz de lo anterior, el único juicio certero que podemos extraer del texto es que todos los fumina perennia son públicos, pero no es posible deducir sin más el posible dominio privado de determinados cursos de agua porque su cauce no es continuo. Desde esta óptica, podría pensarse que el texto está incompleto, pero debemos volver sobre el hecho de que el propósito del fragmento de Ulpiano es esclarecer el concepto utilizado por el magistrado ("flumen publico") y en ello tiene éxito total. Bajo estas circunstancias no es extraño que se deje de lado los cursos menores (rivi); los flumina privata, que solo son mencionados para afirmar la existencia de los públicos y aquellos que tienen una discontinuidad en su cauce y no son navegables (torrentia), que son aludidos para definir la perennidad, que a su vez cuando concurre determina el carácter público del curso en cuestión.

Pero todavía y en el orden de considerar la existencia de la diferenciación flumina publica-flumina privata ${ }^{46}$, no debemos olvidar que Marciano en D. 1, 8, 4, 1 (Marcian. 3 inst.) afirma que casi todos los ríos son públicos, por lo que deja abierta la puerta para entender que aunque con menor importancia, los ríos privados tenían cabida en su pensamiento. Esta forma de entender el pasaje marcianeo ha llevado a parte de la romanística ${ }^{47}$ a sostener que el pasaje de la Institutas de Marciano, hacía referencia a la noción restrictiva de ascendencia cassiana, que entendía como ríos solo a los que fuesen perennes y por lo mismo públicos. Sin embargo, hay dos reflexiones a las que adherimos y que hacen que Fiorentini ${ }^{4}$ esté en desacuerdo con la apreciación previa: en primer lugar, la diferencia habida entre el texto ya referido del Digesto y aquel de las Institutas de Justiniano que es su correlativo ${ }^{49}$, no está suficientemente justificada con el argumento de que en esta última obra se utilizaba en lenguaje más general y menos técnico, pues aquello equivale a sostener que los compiladores habrían sido menos prolijos a la hora de redactar las Institutas, situación que no se basa en ningún vestigio. Por lo demás, de ser así tampoco explica esta teoría el porqué se refieren dos nociones distintas de flumen. Por último, existe todavía otro problema, pues no se acierta en establecer la idea correcta de flumen que nos presenta CAssio, dado que este jurista no dice que los únicos ríos son los públicos, sino que existiendo ríos

\footnotetext{
${ }^{44}$ Martini (1966) p. 387; Gerez Kraemer (2008) p. 153.

45 SEN., Quaest. Nat., 3, 2, 1.

${ }^{46}$ En el mismo sentido, Vid., Alburquerque (2002) p. 213.

${ }^{47}$ Bonfante (1966) pp. 86 ss.

${ }^{48}$ Fiorentini (2003) pp. 92 ss.

${ }^{49}$ Inst. 2, 1, 2
} 
perennes y otros que no lo son, considera que solo los primeros son públicos. Fiorentini demuestra la validez de sus objeciones, trayendo a colación las fuentes bizantinas y particularmente el texto de los Basílicos ${ }^{50}$, pues ellos parecen desmentir el contenido de las Institutas, que declara como públicos a todos los ríos. Pero en el siglo VI d. C. se prefiere la solución del Digesto a la presentada por las Institutas, diferenciando entre ríos públicos y privados, lo que sería incomprensible si en el sistema justinianeo todos los ríos fueran públicos. Ahora bien, tomar partido por esta posición nos lleva a preguntarnos si es posible que Marciano hubiese contemplado la distinción público-privado en sus Institutas y aunque conjetural, no parece inverosímil pensar en una respuesta positiva, lo que haría suponer que posteriormente la diferenciación habría sido eliminada en el intento de los compiladores por ampliar al máximo la categoría de cosas públicas.

Ahora si nos detenemos específicamente en los flumina privados, que son identificados con los torrentes, debemos fijar nuestra atención en el $\$ 2$, en el que Ulpiano establece el criterio para considerar como tal un río: la discontinuidad del aporte hídrico a su corriente, al punto que es claro en señalar que si producto de una gran sequía un río que es perenne pierde todo su cauce no deja de tener dicha calidad por este motivo, pues ello debe ser considerado como un accidente más que una situación regular. Como hemos dicho, de acuerdo a CASsio río perenne y río público son expresiones sinónimas, pero estas nociones no tienen por qué coincidir con el volumen de su caudal pues aquel criterio es válido para diferenciar entre flumen y rivus, pero no para determinar la publicidad o no de los primeros, tal como puede deducirse de D. 43, 20, 3, 1 (Pomp. 34 ad. Sab.), fragmento en que se discute sobre la facultad de derivar agua de un cauce angosto, de pequeñas dimensiones, pero que puede deducirse es público particularmente por el contenido del $\$ 2$, y el hecho de que la preocupación por perjudicar a otros a propósito de la facultad de sustraer agua de un río, solo se justifica en la medida que dicho curso de agua sea público.

Finalmente para determinar la condición jurídica de los cursos de agua no se atiende a la calidad del predio o suelo por el cual escurre, por lo que es perfectamente posible en la visión cassiana, que por un fundo privado escurra un río público, en la medida que él sea perenne. Pero debemos hacer un alto en este punto, pues como decíamos Ulpiano presenta este criterio de la perennidad como probable, lo que da cuenta de que la aceptación al mismo no es absoluta, siendo el fundamento para ello en opinión de Fiorentini ${ }^{51}$, el hecho de que previo a su aceptación operaba otro: el de la accesoriedad respecto de la condición del suelo por el que pasa el curso de agua ${ }^{52}$.

Verifiquemos ahora la situación de los rivi en las fuentes jurídicas y frente a ello uno de los temas más controvertidos dice relación con la posibilidad de restringir el término solo a los cursos artificiales o incluir dentro de él también los naturales.

Un primer elemento de juicio viene dado por un texto donde se refleja la opinión de Quinto Mucio53, quien deja abierta la posibilidad para canalizar el agua a través de ca-

\footnotetext{
${ }^{50}$ Par. Inst. 2, 1, 2 (97, 13 Fe); Bas. 46, 3, 3; Tip. 46, 3, 3; Syn. Bas. 4, 81.

${ }^{51}$ Fiorentini (2003) pp. 87 ss.

52 Mantello (2001) pp. 3 ss. La teoría no es nueva pues ya Scherillo (1945) pp. 107 ss., plantea que el criterio sobre la publicidad de los ríos varió a lo largo de las diferentes épocas.

${ }^{53}$ D. 8, 3, 15 (Pomp. 31 ad Q. Muc.).
} 
ñerías construidas en base a distintos materiales y a propósito de ello se utiliza la expresión "rivo". En definitiva, este pasaje permite teorizar en torno a la idea de que el rivus supone que el agua escurra a través de tuberías y no libremente, por lo que parece ser que el criterio de fondo es que el rivus comprende aquellos cursos de agua cuyo flujo no es necesariamente permanente, de dimensiones más bien modestas y que además tienen la característica de permitir un escurrimiento ordenado del agua, orden que se puede obtener a través de la canalización del mismo por medio de conductos construidos de diversos materiales. La misma situación se observa en el caso de textos epigráficos, como ocurre en la Tabula Contrebiensis $(87 \text { a.C. })^{54}$, donde se contemplan situaciones de canales artificiales y en algunas ocasiones comunitarios ${ }^{55}$.

En cuanto a la vinculación entre rivus y castella, es FESTO quien da un punto de arranque a la cuestión ${ }^{56}$, cuando describe un sistema de repartición del agua basado en un rivus communis, que sirve a una pluralidad de usuarios, los cuales a través de los mecanismos dispuestos en el castellum, conducen el agua hacia sus propios fundos ${ }^{57}$.

Creemos que para dar una vuelta final al asunto, necesariamente debemos volver nuestra mirada hacia el interdicto de rivis, pues precisamente la finalidad del mismo es tutelar los conductos a través de los cuales se ejercita la servitus aquae ductus. En ese contexto, específicamente en D. 43, 21, 1, 2 (Ulp. 70 ad ed.) se hace alusión al origen etimológico del término "rivus", que refiere a la noción de escurrimiento, lo que permite aplicar la palabra a varias hipótesis, situación que claramente resulta en un concepto difuso que finalmente no permite diferenciar entre rivus y flumen, pues por ambos "escurre agua". Sin embargo, todavía debemos considerar un elemento más y que está conectado con la extensión que se da al ejercicio de este interdicto al que se refiere Ulpiano en el $\$ 3$ del mismo texto y que también incluye a los specus y saepta, ambas obras idóneas para desviar agua de un río ${ }^{58}$.

A propósito de los interdictos de aqua cottidiana y aestiva, la referencia a los rivi se hace a propósito de los canales de conducción desde un curso de agua que los alimenta ${ }^{59}$. El "incile" se identifica con la abertura o tajo sobre un curso de un río o lago, que se presenta como equivalente a un rivus o fossae.

Como se puede concluir, el término "rivi" es utilizado de manera bastante extendida en las fuentes, pero se aprecia que en todas las hipótesis en que se hace referencia a él, se entiende que se trata de un cauce de agua de reducidas dimensiones, en definitiva naturales o artificiales que tienen diferentes objetivos.

Una vez resuelto este asunto debemos enfrentar otro problema tanto o más difícil: determinar el régimen jurídico de los rivi, pues aquí caben a lo menos dos posiciones: o solo se les puede considerar privados; o también existen aquellos que podrían ser calificados

\footnotetext{
54 ll, 1-5; 6-10; d’Ors (1980) pp. 1 ss.; Birks, Rodger y Richardson (1984) pp. 45 ss.; Torrent (19821991) II, pp. 261 ss.

55 Esta misma característica se da en el texto epigráfico contenido en CIL, 12, 2426 (=FIRA 3, 71 c).

${ }^{56}$ Paul. Fest., v. dividicula, 62 L.

${ }^{57}$ Fiorentini (2003) p. 142.

${ }^{58}$ Ibid., p. 110.

${ }^{59}$ D. 43, 20, 1, 8 (Ulp. 70 ad ed.).
} 
de públicos. Las principales dificultades derivan precisamente de la amplitud de contenido del término, ya que como recién apuntábamos, con él se designan cursos de agua de dimensiones modestas, pero que pueden ser naturales o artificiales y cuya destinación también es diverso dado que sirven para efectos de irrigación, como objeto de servicio material de un acueducto, o como canalización de desagües.

Un fragmento de Paulo ${ }^{60}$ nos sirve para iniciar el estudio del asunto: en él se discute el ejercicio de la acción de deslinde (actio finium regundorum) en el caso que los fundos contiguos estén separados por un camino o un río público. Sin embargo, y luego de dar la razón de esta solución ${ }^{61}$, prosigue con la sentencia contenida en D. 10, 1, 6 (Paul. 23 ad. ed.) en virtud de la cual la acción se declara admisible, toda vez que se trata de un rivus privado $^{62}$. Nuevamente surge la interrogante de si se trata de un curso natural o artificial y aunque nosotros ya hemos tomado partido por una posición, no podemos obviar que la controversia data desde antiguo, porque ya BÁRTOLO ${ }^{63}$ entendía aquí referido un curso natural, aun cuando con posterioridad existe literatura abundante que se pronuncia en un sentido contrario ${ }^{64}$ y que particularmente fundamenta su posición en el hecho de que cuando las fuentes utilizan el término "rivi" lo harían en relación con un curso de carácter artificial, mismo significado que por lo demás es recogido por FEsto al definir el concepto $^{65}$. Sin embargo, tal como ha sido ya destacado por Gerez Kraemer ${ }^{66}$, si se revisa la reconstrucción de la obra de Paulo en la Palengenesia ${ }^{67}$, resulta ser que el orden lógico que debió tener el libro ad edictum que nos interesa es respetado por los compiladores: aparece en primer lugar la cuestión de si existe un flumen o una vía pública en el límite del predio y posteriormente la de un rivus. La lógica seguida con posterioridad es implecable: la actio finium regundorum no es posible en los dos primeros casos, porque ambos son públicos lo que permite por sí mismos determinar el límite de la finca. Pero, además en el caso del flumen no hay discrepancias en la doctrina en cuanto a que este tiene es un curso natural y entonces, cuando con posterioridad el jurista se refiere al rivus, sin especificación de si es natural o artificial, no hay razón para entender que con él señala solo conductos de esta última categoría. Muy por el contrario, la diferencia entre las dos hipótesis planteadas en el texto de Paulo se basa no la distinción natural-artificial, sino en la diferenciación públicoprivado, lo que explicaría, por lo demás la insistencia de nuestro jurista en destacar la titularidad del rivus.

En este punto parece adecuado analizar el contenido de algunas leyes públicas que traen incorporados en su texto elementos que nos sirven para discernir sobre el asunto. Especialmente importante es la lex Ursonensis en la que se emplea el término "rivus" como

\footnotetext{
${ }^{60}$ D. 10, 1, 4, 11 (Paul. 23 ad ed.).

${ }^{61}$ D. 10, 1, 5 (Paul. 15 ad Sab.)

${ }^{62}$ Daube (1957) pp. 39 ss.

${ }^{63}$ De insula 11,2 . Este jurista alude al arroyo como cauce natural y refiere a propósito de aquello el texto de Paulo que estamos enfrentando.

${ }^{64}$ Gerez Kraemer (2008) pp. 138.

${ }^{65}$ Karadge (1928) pp. 54 ss.

${ }^{66}$ Gerez Kraemer (2008) p. 139.

${ }^{67}$ Pal. I, c. 1013-1014, \$379.
} 
equivalente a curso natural de agua, cuya magnitud lo ubica en una zona intermedia entre el flumen y las fontes, lo que está en armonía con el criterio expresado por Ulpiano en D. 43, 12, 1, 1 (Ulp. 70 ad ed.), y revela en cierta medida los criterios que pudieron haberse utilizado para resolver el problema que estamos desarrollando ${ }^{68}$ : en este sentido se optó por mantener el mismo estado de cosas que existía previo a la fundación de la colonia, de modo que aquellas aguas que eran públicas se mantuvieron en su calidad de tales y otro tanto ocurrió con aquellas que eran catalogadas de privadas ${ }^{69}$. En suma, el uso público o privado de las aguas, determina la suerte de las mismas.

Ahora debemos volver a los presupuestos del interdicto de rivis, particularmente en el testimonio de Ulpiano contenido en D. 43, 21, 3, 4 (Ulp. 70 ad. ed.), que da a conocer la utilidad del interdicto tanto respecto de las acequias que corren por un terreno privado, como en relación a aquellas que lo hacen en uno público y en este sentido se debe ser sumamente cuidadoso, pues lo calificado como público o privado no es el rivus, sino el predio por el cual corre. Inmediatamente surge la pregunta de si la calidad del suelo se comunica al rivus o este mantiene su independencia y por tanto un régimen jurídico que le es propio.

Claramente hemos determinado que tanto los presupuestos como la legitimación al ejercicio del interdicto de rivis, se encuadra dentro del contexto de las relaciones entre privados, pero aquello no es decidor para proclamar sin más a todos los rivi como privados, especialmente si nos fijamos en el régimen de los interdictos de aqua cotidiana y de aqua aestiva, en los que se denota que el rivus es totalmente funcional al ejercicio de la servitus, por lo que su naturaleza pública o privada no tiene mayores consecuencias. De hecho, cuando Ulpiano manifiesta el presupuesto básico de concesión del interdicto, para nada se refiere a la categoría del conducto a través del cual se ejerce la servidumbre, sino a la calidad del agua que debe ser perenne ${ }^{70}$.

Ahora bien, una primera solución podría darse a través del recurso de la analogía pues es factible sostener que a los rivi se les aplican los mismos principios que a los flumina, es decir que la categoría de público o privado estará determinada por la perennidad de sus aguas. Pero como ha establecido Gerez Kraemer ${ }^{71}$, si bien el argumento tiene lógica, el encabezado del comentario de Ulpiano hace que sea descartado, pues en él nuestro jurista separa radicalmente los flumina de los rivi y aun cuando los criterios que enuncia para realizar esta diferenciación podrían ser relativamente discutibles, lo que no resulta serlo es la intención de marcar la distinción entre un tipo de curso y otro. Esto conlleva necesariamente a mantener un esquema en que el criterio de la perennidad se encuentra absolutamente vinculado a los flumina, por lo que los rivi quedan excluidos de él ${ }^{72}$. De esta forma es factible pensar en que los rivi son cursos de agua que tienen una configuración autónoma, cuya titularidad queda entregada en definitiva a los usos que sobre ellos realizan

${ }^{68}$ Gerez Kraemer (2008) p. 142 n. 340, hace una rica relación de fuentes epigráficas en la que se menciona el término "rivus".

${ }^{69}$ Lex Ursonensis, C. LXXIX.

${ }^{70}$ D. 43, 20, 1, 5 (Ulp. 70 ad ed.); Cursi (2002) pp. 161 ss.

${ }^{71}$ Gerez Kraemer (2008) pp. 144 ss.

72 Bonfante (1966) p. 76; Scherillo (1945) p. 110. 
las poblaciones locales; o bien, la titularidad del suelo por el cual escurren ${ }^{73}$, cuestión que tiene cierta base, sobre todo si tomamos en consideración el texto previamente aludido de la lex Ursonensis.

Sin embargo, hay una cuestión que llama profundamente la atención, pues si bien somos categóricos en señalar la existencia independiente de rivi públicos y privados, resulta ser que en relación a los primeros no existe tutela jurídica alguna que nos haya llegado a través de las fuentes: en D. 43, 12, 1, 12 (Ulp. 68 ad ed.) se refiere un interdicto que está destinado solo a los flumina publica navigabilia, pero que en los tiempos de LABEón ya se encuentra extendido vía útil hacia los flumina no navigabilia, el que se suma a los otros dos que menciona Ulpiano en el mismo Título 12 del Libro 43, también para el mismo tipo de cursos de agua ${ }^{74}$, por lo que finalmente se presenta un cuadro en el que todos los $f u$ mina publica, navegables o no, están tutelados respecto de su uso. Por el contrario los rivi publica no tienen protección específica, salvo la general que se puede obtener a través de los interdictos de locis et itineribus publicis ${ }^{75}$ y ne quid in loco publico vel itinere fiat ${ }^{76}$. Desde esta perspectiva no es ilógica la conclusión de Gerez Kraemer ${ }^{77}$ en orden a entender que respecto de los cursos menores de agua, los romanos detuvieron su atención más bien en aquellos que son considerados como privados, tal como lo demuestra la continua referencia a ellos que encontramos en los escritos extrajurídicos ${ }^{78}$ y respecto de esta última calificación, esta dependía del régimen del suelo por el que escurrían.

Por último, resulta interesante analizar como parte de la romanística ${ }^{79}$ sostiene que para establecer la publicidad de un río, también debe concurrir copulativamente la navegabilidad del mismo, a lo que podemos argumentar en contra que nada de ello nos señalan las fuentes, tal como ya hemos tenido oportunidad de verificar, sumado a la circunstancia de que la posibilidad de navegar en un río es una de las formas de utilización posible del mismo, pero no una definición ${ }^{80}$, lo que queda demostrado en el hecho de que la tutela prestada por los interdictos que se refieren a ella, no lo hacen en forma exclusiva sino que también incluyen la posibilidad de atraque de las naves ${ }^{81}$. La tesis recién expuesta es compartida por una serie de autores entre los que destacan Bonfante ${ }^{82}$, Longo ${ }^{83}$ y Alberta$\mathrm{RIO}^{84}$ y que adicionan como argumento el hecho de que el estado hidrográfico de la Italia antigua excluye la navegabilidad de la mayoría de los ríos y por lo mismo, la relevancia jurídica de dicho aspecto.

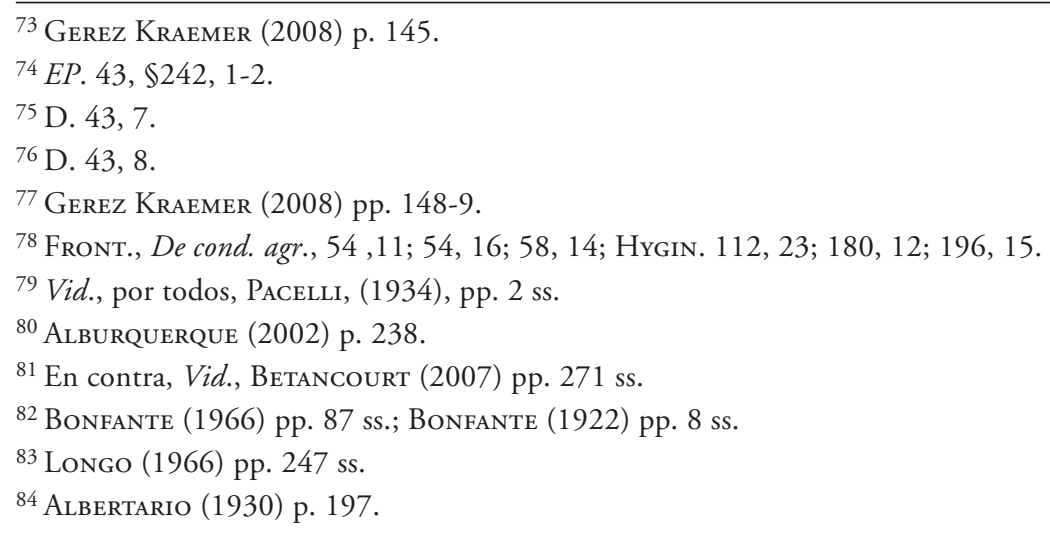


Por lo demás y en el mismo sentido, no podemos menos que estar de acuerdo con FioRENTINI $^{85}$ en que las siguientes observaciones permiten prescindir de la navegabilidad como elemento definitorio de los ríos públicos: hay cursos de agua perennes que no son aptos para la navegación ${ }^{86}$ y; si se busca un segundo requisito en cuanto a la posibilidad de dar la categoría de público, él más bien subyace en la utilidad del curso de agua a las necesidades de la colectividad (publica utilitas; usus publicus), que en el carácter navegable del mismo.

\section{III. "INTERDICTUM NE QUID IN FLUMINE PUBLICO RIPAVE EIUS FIAT, QUO PEIUS NAVIGETUR ${ }^{87 "}$}

Frente al estudio del interdicto enunciado previamente, debemos precisar que deben tratarse dos modalidades del mismo: uno prohibitorio y otro restitutorio.

\section{INTERDICTO PROHIBITORIO}

El interdicto al que dedicaremos este apartado, se concede cuando en el cauce o en la ribera de un río público, se realizan obras o intervenciones que comprometen la navegación (iter) o el atraque (statio) de las naves ${ }^{88}$ :

D. 43, 12, 1, pr. (Ulp. 68 ad ed.)

Ait praetor: 'Ne quid in flumine publico ripave eius facias neve quid in flumine publico neve in ripa eius immittas, quo statio iterve navigio deterior sit fiat'.

Por su parte el $\$ 12$ del mismo fragmento, refiere la opinión de LABEón, que amplía la hipótesis original de concesión a la que aludimos previamente:

D. 43, 12, 1, 12 (Ulp. 68 ad ed.)

Non autem omne, quod in flumine publico ripave fit, coercet praetor, sed si quid fiat, quo deterior statio et navigatio fiat. ergo hoc interdictum ad ea tantum flumina publica pertinet, quae sunt navigabilia, ad cetera non pertinet. sed Labeo scribit non esse iniquum etiam si quid in eo flumine, quod navibabile non sit, fiat, ut exarescat vela aquae cursus impediatur, utile interdictum competere ne vis ei fiat. quo minus id opus, quod in alveo fluminis ripave ita factum sit, ut iter cursus fluminis deterior sit fiat, tollere demoliri purgare restituere viri boni arbitratu possit.

\footnotetext{
${ }^{85}$ Fiorentini (2003) pp. 153 ss.

${ }^{86}$ Particularmente interesante en este sentido es el análisis de D. 43,12, 1, 12 ( Ulp. 68 ad ed.), en el que Ulpiano trae a colación la opinión de LABEón, respecto de la extensión por vía "útil" del interdicto "ne quid in flumine publico ripave eius fiat, quo peius navigetur", y sobre el que tendremos oportunidad de pronunciarnos latamente en la siguiente sección.

${ }^{87}$ EP 43\$241; Costa (1918) pp. 14 ss.; SCialoja (1928) pp. 212 ss.; Biscardi (1938) pp. 22 ss.; Segrè (1941) pp. 17 ss.; Branca (1941) pp. 29 ss.; Burdese (1957), VII, pp. 414 ss.; Capogrossi Colognesi (1966), pp. 907 ss.; Gómez Royo (1997) pp. 55 ss.; Zoz (1999) pp. 148 ss.; Lazo (1999) pp. 65 ss.

${ }^{88}$ Lazo (1999) p. 69.
} 
Como puede apreciarse, en la primera parte del texto recién reproducido se afirma que el interdicto solo puede concederse cuando las actividades señaladas en el \$pr., afecten ríos que reúnan copulativamente dos características: deben ser públicos y además navegables. Pero luego y siguiendo la opinión de LABEón, se adiciona la circunstancia de que también puede ser concedido, vía útil, aun cuando el curso de agua afectado no sea navegable. Respecto de esta última opinión, la doctrina no se encuentra conteste en cuanto a su autenticidad, pues hay quienes se pronuncian a favor de ella y otros que, por el contrario la rechazan: estos últimos ${ }^{89}$ sostienen que la misma sería responsabilidad de editores y reelaboradores postclásicos de la obra de UlPiAno que habrían traído el inciso referido a la ampliación desde otro lugar de la misma obra o derechamente de una obra distinta y de la cual no se guarda registro. Excluyen entonces, la posibilidad de una intervención compilatoria directa, lo que quedaría demostrado de acuerdo a BERGER ${ }^{90}$, en la recopilación repetitiva de los antecedentes habidos en los $\$ 12$ y $\$ 18$, en relación al $\$ 17$, todos del mismo fragmento, lo que se debería en su opinión a un glosema. Alburquerque ${ }^{91}$, se ha dado a discutir esta hipótesis, en el sentido de que de la argumentación dada por BERGER, lo único que permite concluir con meridiana claridad es la duda que recae sobre la ubicación de los fragmentos enunciados, pero nada más.

A su vez pronunciándose por la autenticidad del inciso, Di PORTO ${ }^{92}$ suscribe la idea de que ella se justifica en el interés de la defensa del ambiente fluvial, es decir de la condición natural de los ríos, razón más que suficiente, para que LABEón se pronunciara sobre el asunto $^{93}$. En la misma línea BrANCA ${ }^{94}$, en contra de las opiniones de Bonfante ${ }^{95}$ y AlberTARIO $^{96}$, supone que si existe una modificación textual esta es netamente formal ${ }^{97}$ y nada tiene que ver con el núcleo del pasaje, el que es auténtico.

Para tomar una posición definitiva sobre el asunto, parece necesaria realizar alguna precisión en torno a la parte del fragmento que ahora nos interesa, especialmente la que dice relación con el hecho de que Labeón no utiliza el adjetivo "publicus" en ella, lo que puede entenderse en términos de incluir tanto los cursos de agua que cuentan con dicha característica como aquellos que carecen de ella. Ahora, se debe tener presente que si bien esto abre la posibilidad a integrar hipótesis no incluidas originalmente para la aplicación del interdicto, aquello no significa que dentro de ellas se considere la posibilidad de cursos de agua no navegables, pues hay que recordar que la calidad de río público depende de la perennidad del curso de agua y no de su navegabilidad. A propósito de esto conviene detenerse en un pasaje de ULPIANO ${ }^{98}$, que pareciera admitir la posibilidad de conceder nuestro interdicto en el caso

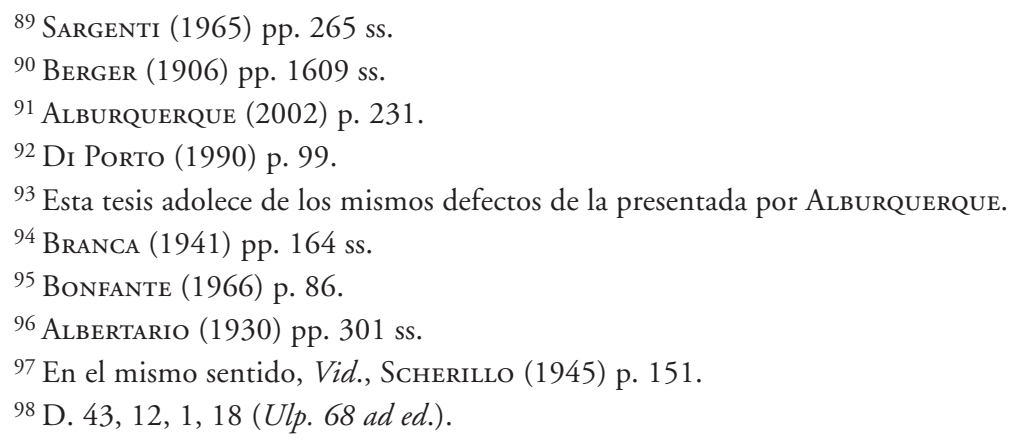


de ríos no navegables, pero LABRUNA ${ }^{99}$ resalta el hecho de que resultaría absurdo pensar en este supuesto, toda vez que el recurso está destinado a impedir el facere y el immittere que perjudica la navegabilidad de un río público. La explicación estaría en la recepción y aceptación por parte de UlPiANo del criterio de LABEón en torno a dar una amplísima tutela a todos los ríos públicos, navegables o no, argumento que no puede ser considerado infundado, particularmente si pensamos que en esa línea se inscribe el contenido de D. 43, 13, 1, 2 (Ulp. 68 ad ed.), extraído del mismo libro de Ulpiano, pero referido al interdicto "ne quid in flumine publico fiat, quo aliter aqua fluat, atque uti priore aestate fluxit", en el que se hace alusión a los ríos públicos, sin distinguir respecto de la posibilidad de navegación en ellos.

Solo una vez reunidos estos diversos elementos, podemos tomar partido por la autenticidad del inciso en discusión, que manifiesta claramente un principio que hacia fines de la época clásica y especialmente en la postclásica, se hace de general aceptación y absolutamente acorde con las nuevas orientaciones del régimen jurídico vinculado a las aguas ${ }^{100}$.

Sin perjuicio de lo expresado previamente, debemos ser enfáticos en cuanto no existen dudas razonables respecto de que en su configuración original, el interdicto motivo de este apartado solo se refería a los ríos navegables, pues dicha actividad es precisamente la que se encuentra tutelada.

En lo que dice relación con la extensión de la tutela, Ulpiano al exponer los diferentes aspectos vinculados a este interdicto, alude tanto a las orillas como al cauce del río, lo que para algunos encuentra su razón de ser en el hecho de que para los juristas el curso de agua era un todo, del que no podían separarse sus componentes ${ }^{101}$, opinión que no podemos tildar de ilógica, pero que no resulta tan sólida si se atiende a la polémica abierta a propósito de la calificación como públicas o privadas de las orillas y así conviene detenerse en este asunto, para lograr un mejor entendimiento de la problemática. Revisadas las fuentes que pueden ser útiles, nos encontramos en primer término con la siguiente:

\section{43, 12, 1, 5 (Ulp. 68 ad ed.)}

Ripa autem ita recte definietur id, quod flumen continet naturalem rigorem cursus sui tenens: ceterum si quando vel imbribus vel mari vel qua alia ratione ad tempus excrevit, ripas non mutat: nemo denique dixit Nilum, qui incremento suo Aegyptum operit, ripas suas mutare vel ampliare, nam cum ad perpetuuam suit mensuram redierit, ripae alvei eius muniendae sunt. si tamen naturaliter creverit, ut perpetuum incrementum nanctus sit, vel alio flumine admixto vel qua alia ratione, dubio procul dicendum est ripas quoque eum mutasse, quemamodum si alveo mutato alia coepit currere.

El fragmento nos da a conocer el concepto de "orilla" y él hace alusión al flujo natural y a un nivel habitual de las aguas, es decir a su curso normal ${ }^{102}$. Un criterio distinto presenta PAUlo, quien conceptualiza en los siguientes términos:

\footnotetext{
99 Labruna (1970) p. 61.

${ }^{100}$ En este mismo sentido debe ser descartada la tesis que ve en la ampliación de la órbita de aplicación del interdicto, la defensa del carácter perenne del curso de agua. Vid., Lozano (1982) p. 190.

101 Vid., por todos, Fiorentini (2003) p. 164.

102 Alburquerque (2002) pp. 257-8.
} 


\section{43, 12 ,3 , 1-2 (Paul. 16 ad Sab.)}

Ripa ea putatur esse, quae plenissinum flumen continet.(2) Secundum ripas fluminum loca non omnia publica sunt, cum ripae cedant, ex quo primun a plano vergere incipit usque ad aquam.

De acuerdo a este jurista, la orilla sería aquella demarcada por el río cuando tiene su cauce más crecido y estaría constituida por la porción de terreno que va en declive hasta el nivel o superficie del agua. Indudablemente se trata de un concepto más amplio, pues incluye una extensión de terreno inmediatamente vecina al curso de agua propiamente tal ${ }^{103}$ : es un criterio mucho más práctico y con él se puede afirmar que las orillas de los ríos públicos comprenden, a lo menos una parte de los fundos adyacentes.

Un problema distinto, pero conectado con el anterior, dice relación con determinar si las orillas también deben ser consideradas públicas o siguen siendo privadas, pero susceptibles de ser usadas por todos. Las opiniones jurisprudenciales son dispares, pero a favor del carácter público de las orillas se pronuncian PAULO ${ }^{104}$; LABEÓN ${ }^{105}$ y ULPIANO ${ }^{106}$; mientras que por las tesis contraria están POMPONIO ${ }^{107}$ y GAYO ${ }^{108}$.

De acuerdo a Alburquerque ${ }^{109}$ y seguimos su criterio, existe dominio privado sobre las orillas, pero este se encuentra limitado por el uso normal de las mismas reconocido a todos para el desempeño de actividades propias de la navegación, las que deben ser permitidas por el dominus del predio colindante con el cauce de agua, pues de lo contrario quedará sujeto a los términos del interdicto ${ }^{110}$.

Bajo estas mismas premisas puede plantearse la polémica en torno a la titularidad del cauce abandonado, pues el siguiente fragmento se enfrenta a las consecuencias jurídicas generadas a partir de la ocurrencia de dicha hipótesis:

\section{43, 12, 1, 7 (Ulp. 68 ad ed.)}

Simili modo et si flumen alveam suum relliquit et alia fluere coeperit, quidquid non pertinet: non enim in flumine publico factum erit, quod est utriusque vicini aut, si limitatus est ager, occupantis alveus fiet: certe desinit esse publicus. ille etiam alveus, quem sibi flumen fecit, etsi privatus ante fuit, incipit tamen esse publicus, quia impossibile est, ut alveus fuminis publici non sit publicus.

\footnotetext{
103 Ibid., p. 259.

${ }^{104}$ D. 43, 12, 3 pr. (Paul. 16 ad Sab.).

105 D. 41, 1, 65, 1 (Lab. 6 pith.).

${ }^{106}$ D. 39, 1, 1, 1 (Ulp. 52 ad ed.).

107 D. 41, 1, 30, 1 (Pomp. 34 ad Sab.).

108 D. 1, 8, 5 (Gai. 2 rer. cott.).

${ }^{109}$ Alburquerque (2002) p. 264.

${ }^{110} \mathrm{El}$ asunto no es fácil, porque de acuerdo al criterio tantas veces expuesto en orden a que el dominio en Roma, es concebido en términos absolutos podría pensarse en que el dominus del fundo colindante tiene la facultad de impedir cualquier immissio en su predio. Pero la problemática debe analizarse desde la perspectiva que supone la dinámica general de los interdictos: la posibilidad de conciliar los intereses públicos con los privados.
} 
En relación a este texto la doctrina ha oscilado entre dos tesis: aquellos que sostienen que el cauce de un río es a lo menos en potencia, de los dueños de los predios ribereños ${ }^{111}$, y aquellos que consideran que muy por el contrario el cauce de un río que tiene la calidad de público, también lo es ${ }^{112}$. Trataremos de tomar posición respecto de la problemática aquí planteada, basándonos en el texto sobre la cual se ha sustentado la discusión:

\section{41, 1, 7, 5 (Gai. 2 rer. cott.)}

Quod si toto naturali alveo relicto flumen alias fluere coeperit, prior quidem alveus eorum est, qui prope ripam praedia possident, pro modo scilicet latitudinis cuiusque praedii, quae latitudo prope ripam sit: novus autem alveus eius iuris esse incipit, cuius et ipsum flumen, id est publicus iuris gentium. quod si post aliquod temporis ad priorem alveum reversum fuerit flumen, rursus novus alveus eorum esse incipit, qui prope ripam eius preadia possident. cuius tamen totum agrum novus alveus occupaverit, licet ad priorem alveum reversum fuerit flumen, non tamen is, cuius is ager fuerat, stricta ratione quicquam in eo alveo habere potest, quia et ille ager qui fuerat desiit esse amissa propria forma et, quia vicinum praedium nullum habet, non potest ratione vicinitatis ullam partem in eo alveo habere; sed vix est, ut id optineat.

En este caso, se trata del cambio del cauce de un río y se resuelve en el sentido que el nuevo cauce también es público y ello por derecho de gentes, lo que nos lleva a concluir que el álveo de un río público debe considerarse dentro de la misma categoría de cosa aun cuando su nuevo curso por mutaciones naturales implique que ahora escurre en un predio privado $^{113}$. En ese caso el anterior cauce pasa a quedar bajo el dominium de los titulares de los predios ribereños. Como es lógico de suponer, el mismo criterio se ve expuesto esta vez en un pasaje de las Institutas de Justiniano y en otro texto del Digesto:

Inst. 2, 1, 23

Quodsi naturali alveo in universum derelictio alia parte fluere coeperit, prior quidem alveus eorum est, qui prope ripam eius praedia possident, pro modo scilicet latitudinis cuiusque agri, quae latitudo prope ripam sit, novus autem alveus eius iuris esse incipit, cuius et ipsum flumen, id est publicus. quodsi post aliquod tempus ad priorem alveum reversum fuerit flumen, rursus novus alveus eorum esse incipit, qui prope ripam eius praedia possident.

D. 41, 1, 30, 3 (Pomp. 34 ad Sab.)

Alluvio agrum retituit eum, quem impetus fluminis totum abstulit, itaque si ager, qui inter viam publicam et flumen fuit, inundatione fluminis occupatus esset, sive paulatim occupatus est sive non paulatim, sed eodem impetu recessu fluminis restitutus, ad pristinum dominum pertinet: flumina enim censitorum vice funguntur, ut ex privato in pu-

\footnotetext{
111 Guarneri Citati (1926) pp. 107 ss.

112 Scialoja (1928) pp. 218 ss.; Grosso (1941) pp. 138-140; Scherillo (1945) pp. 111 ss.

113 Alburquerque (2002) p. 245.
} 
blicum addicant et ex publico in privatum: itaque sicuti hic fundus, cum alveus fluminis factus esset, fuisset publicus, ita nunc privatus eius esse debet, cuius antea fuit.

SCIALOJA ${ }^{114}$ cree que el principio aplicado parece fundarse en que para el Derecho Romano el lecho de un río es considerado como una res publica, siempre que no haya sido asignado a los privados. Como muestra de aquello puede invocarse la diversidad terminológica que aparece en las fuentes: en las Institutas de Justiniano y Ulpiano como "publicus"; mientras que GaYo lo denomina "publicus iuris gentium".

Por su parte, entre los que están por la tesis de que el cauce del río queda bajo el dominio de los dueños de los predios ribereños, se encuentra BrancA ${ }^{115}$, quien sostiene que los fragmentos de D. 41, 7, 5 (Gai 2 rer. cott.); D. 41, 1, 30, 3 (Pomp. 34 ad Sab.) e Inst. 2, 1, 23, están alterados ${ }^{116}$, aun cuando no sustenta con demasiados argumentos su posición. En contra, Scherillo ${ }^{117}$ presenta una tesis que resulta interesante, pues para él la condición jurídica del cauce abandonado está determinada por la circunstancia de si el río escurre entre agri limitati o agri arcifini: en el primer caso, de los textos que nos llegan a través de los agrimensores ${ }^{118}$, el cauce seguía siendo público, pero de acuerdo a UlpiA$\mathrm{NO}^{119}$, la cuestión es diferente pues pierde dicho carácter y pasa a ser un res nullius. Esta contradicción, de acuerdo a nuestro autor, se basa en el hecho de que los agrimensores dan cuenta de una doctrina más antigua y UlpiANo de una más reciente, que es la consecuencia práctica de un asunto más profundo: en la época de los agrimensores el criterio utilizado es el del carácter del suelo por el que escurre el río; en cambio en la sentencia de Ulpiano, lo que prima es el criterio de la perennidad. Ahora bien, si el río escurre por los agri arcifinii, el cauce abandonado es adquirido por los propietarios de los fundos ribereños hasta el punto medio del río ${ }^{120}$.

Sin perjuicio de que la discusión de la romanística sobre el particular es intensa y solo hemos detallado algunos aspectos de ella, podemos sostener que desde Scialoja ${ }^{121}$, Grosso $^{122}$, Scherillo ${ }^{123}$, Astuti ${ }^{124}$, Robbe ${ }^{125}$, Zoz $^{126}$ y últimamente Alburquerque ${ }^{127}$,

\footnotetext{
${ }^{114}$ SCialoja (1928) p. 220.

115 Branca (1941) pp. 58 ss.

$116 \mathrm{El}$ autor realiza un interesante análisis de las diferentes posiciones doctrinarias sobre el tema y termina afirmando que la complicada evolución del régimen del álveo abandonado está constituido por el principio de la adquisición del terreno a los dueños ribereños, que es introducido en la época clásica tardía o primer periodo de la época postclásica y sancionado definitivamente por Justiniano en el Corpus Iuris.

117 Scherillo (1945) pp. 112 ss.

${ }^{118}$ Front., De contr. agr., 20, 10; 50, 15.

${ }^{119}$ D. 43, 12, 1, 7 (Ulp. 68 ad ed.).

${ }^{120}$ Alburquerque (2002) p. 249.

${ }^{121}$ Scialoja (1928) p. 218.

122 Grosso (1941) p. 137.

${ }^{123}$ SCherillo (1945) p. 111.

${ }^{124}$ Astuti (1958) T 1, p. 354.

${ }^{125}$ Rовве (1979) pp. 684 ss.

${ }^{126} \mathrm{Zoz}(1999)$ p. 95.

${ }^{127}$ Alburquerque (2002) p. 251.
} 
se ha seguido el camino de adherir a la opinión que otorga la calidad de público al cauce de un río, tesis por la que nosotros también nos inclinamos. Ahora como muy acertadamente señala SARGenti ${ }^{128}$, a propósito del cauce abandonado y toda vez que deja de ser un río, el interdicto no le es aplicable. De hecho el mismo Ulpiano reconoce esta situación en el siguiente fragmento:

D. 43, 12, 1, 10 (Ulp. 68 ad ed.)

Item si amnis aliquid circumeat, sciendum est eius manere cuius fuit: si quid igitur illic factum est, non est factum in publico flumine. nec pertinet ad hoc interdictum, si quid in privatum factum sit, ne quidem si in privato flumine fiat: nam quod fit in privato flumine, perinde est, atque si in alio privato loco fiat.

Tampoco se aplica el interdicto cuando ocurre una inundación, pues los efectos de ella no cambian la consideración jurídica del predio afectado:

D. 41, 1, 7, 6 (Gai. 2 rer. cott.)

Alliud sane est, si cuius ager totus inundatus fuerit: namque inundatio speciem fundi non mutat et ob id, cum recesserit aqua, palam est eiusdem esse, cuius et fuit.

D. 43, 12, 1, 9 (Ulp. 68 ad ed.)

Aliter atque si flumen aliquam terram inundaverit nom alveum sibi fecerit: tunc enim non fit publicum, quod aqua opertum est.

Pese a lo anterior el interdicto de fluminibus si extiende su aplicación a las fosas o canales que se hayan abierto de manera artificial, siempre que el río que escurra por ellas sea público:

D. $43,12,1,8$

Si fossa manu facta sit, per quam fluit publicum flumen, nibilo minus publica fit: et ideo si quid ibi fiat, in flumine publico factum videtur.

Las fosas o canales pasan a ser públicos y la sentencia contenida en este fragmento lo confirma ${ }^{129}$. Por su parte el concepto de fosa artificial manejado por ULPIANO aparece referido en el siguiente fragmento:

D. 43, 14, 1, 5-6 (Ulp. 68 ad ed.)

Fossa est receptaculum aquae manu facta. (6) Possunt autem etiam haec esse publica.

Aun cuando UlPiano no haga referencia a la magnitud de la fosa o canal, tenemos que suponer que se trata de aquellas preparadas para la navegación en general y al amarre

\footnotetext{
128 SARgenti (1965) p. 265.

${ }^{129}$ Alburquerque (2002) p. 255.
} 
de las embarcaciones, por tratarse de aspectos fundamentales protegidos por el interdicto. Sin perjuicio de que no tenemos argumentos sólidos para sostener nuestra opinión, parece llamativa la extensión del interdicto a estos casos, particularmente por el hecho de que no es fácil desde el punto de vista material, el cavar fosas o canales que permitan la navegación y tal vez la explicación pueda darse en términos de que esta idea es materialización del interés postclásico por dar amparo a todas las aguas, sin importar las calificaciones que eran sustento de la discusión jurisprudencial previa.

Para efectos de dar término al análisis del objeto de la tutela, es necesario señalar que el interdicto era concedido no solo en el caso de obras idóneas para perjudicar la navegación o el atraque en el río público, sino también en el caso de que se produjera una turbación o impedimento del iter terrestre; todo ello con miras a salvaguardar el acceso a las naves. A esto se refiere la parte final de D. 43, 12, 1, 14 ( $U l p .68$ ad ed.).

En el análisis del texto del interdicto, el concepto de "nave" resulta esencial para comprender el alcance del mismo, pues él tiene particular incidencia en lo que dice relación con el interés activo vinculado al mismo:

D. 43, 12, 1, 14 (Ulp. 68 ad ed.)

Ait praetor: 'itemque navigii deterius fiat'. hoc pro navegatione positum est: immo navigium solemus dicere etiam ipsam navem, iter ergo navigio potest et sic accipi 'iter navi deterius fiat'; navigii appellatione etiam rates continentur, quia plerumque et ratum usus necessarius est.

Considerando que el objetivo de la tutela interdictal es proteger la navegación en toda su amplitud el texto del pasaje recién reproducido no puede sorprender pues se refiere a naves de diversa entidad y dimensiones. Pese a ello el análisis del fragmento no ha sido pacífico pues De Martino ${ }^{130}$ ha sostenido que la alusión a las "rates" sería obra de los compiladores, tesis discutida por FIORENTINI ${ }^{\mathrm{I} 3 \mathrm{I}}$, cuyos argumentos hacemos nuestros pues el término "navigium" en el contexto de este interdicto se refiere a la navegación como acto $(\$ 14)$, aun cuando en la práctica se utiliza para designar la nave en su entidad material. La conclusión es que ULPIANo no hace más que registrar la discrepancia entre el uso técnico del término y aquel utilizado en la lengua común ${ }^{132}$. Esto mismo hace necesario determinar qué tipo de embarcaciones están bajo la óptica del pretor, especialmente porque como ha destacado Fiorentini ${ }^{133}$, las embarcaciones fluviales son distintas no solo por su tamaño sino también por las técnicas de navegación utilizadas. Así se pueden incluir embarcaciones de grandes dimensiones y botes pequeños destinados a la pesca, dado que estos últimos pueden atracar casi en cualquier lugar y, por el contrario, las primeras requieren de la infraestructura propia de un puerto.

\footnotetext{
${ }^{130}$ De Martino (1982) pp. 48 ss.

${ }^{131}$ Fiorentini (2003) p. 165.

132 Por lo demás se trata de un uso lingüístico utilizado en las fuentes extrajurídicas: Vid., Plin., Nat. hist., 3, 50.

133 Fiorentini (2003) pp. 166-7.
} 
En consecuencia, es muy verosímil pensar que el pretor hubiese tutelado todas las hipótesis que suponen el concepto de nave en su acepción más amplia, prohibiendo la construcción de obras que llegaren a representar una turbación para la navegación o atraque de ellas ${ }^{134}$.

Los actos a los que nos referiremos se incluyen dentro del significado del término "incommodum" y para desentrañarlo, el punto de partida se encuentra en el siguiente texto:

D. 43, 12, 1, 13 (Ulp. 48 ad ed.)

Stationem dicimus a stando: is igitur locus demonstratur, ubicumque naves tuto stare possunt.

El fragmento tiene por objetivo fijar los conceptos de “iter" y "statio", y en este afán la frase "iter deterior" no representa problemas de entendimiento, pues claramente indica el perjuicio que afecta el acto de navegar. Otra cosa es la de enfrentar las turbaciones a la "statio", dado que la referencia a un lugar cualquiera en que la nave puede ser atracada (" $u b i$ cumque naves tuto stare possunt"), permite concluir que la "statio" no solo implica alusión a un puerto en el sentido más propio, sino a cualquier lugar que sirva para el atraque de las naves. En dicho sentido es propicio acudir a otro pasaje del mismo Ulpiano:

\section{50, 16, 59 (Ulp. 68 ad ed.)}

'Portus' appellatus est conclusus locus, quo importantur merces et inde exportantur: eaque nibilo minus statio est conclusa atque munita. Inde 'angipotum' dictum est.

Resulta evidente la diversidad terminológica, dado que en este último fragmento se vincula la "statio" a un lugar dotado de protección e instalaciones propias de las actividades de carga y descarga de mercancías (lo que modernamente denominamos en un sentido más propio "puerto").

En consideración de esta amplísima concepción, no es ilógico que la fórmula del interdicto distinga las actividades realizadas en el lecho del río y aquellas realizadas en la ribera del mismo:

D. 43, 12, 1, 11 (Ulp. 48 ad ed.)

In fumine publico factum accipere debemus, quidquid in aqua fiat, nam si quid extra factum sit, non est in flumine factum: et quod in ripa flat, non videtur in flumine factum.

Hay aquí una enumeración de diferentes actos de turbación referidos al facere y al immittere in flumine en relación a la corriente (in aqua); o bien, en el cauce, en tanto que la immissio sobre la ribera no estaba comprendida en una cláusula diversa: la fórmula inclusiva del texto evita que aquel contra quien va dirigido alegue que su obra no está incluida dentro de las hipótesis de prohibición: con la expresión "facere” el pretor veta la realización de obras que obstaculicen de cualquier modo la navegación; por su parte el verbo "immitte-

${ }^{134}$ Rougé (1966) p. 330. 
re” tiene un contenido más amplio, que incluye muchas actividades tales como la construcción de obras permanentes o incluso la descarga de escombros ${ }^{135}$.

La ejemplificación exacta de los eventos que dan lugar a la concesión del interdicto nos la entrega el siguiente fragmento:

\section{43, 12, 1, 15 (Ulp. 68 ad ed.)}

Deterior statio itemque iter navigio fieri videtur, si usus eius corrumpatur vel difficilior fiat, vel deterior aut si in tottum auferatur. Proinde sive derivetur aqua, ut exiguior facta minus sit navigabilis, vel si dilatetur, aut diffusa brevem aquam faciat, vel contra sic coangustetur, et rapidius flumen faciat, vel si quid aliud fiat quod navigationem incommodet difficilioremve faciat vel prorsus impediat, interdicto locus erit.

De acuerdo al texto, el esquema que se debe seguir es el siguiente:

$1^{\circ}$. El interdicto debe concederse cuando se hace imposible el uso del curso de agua, ya sea para practicar la navegación o para el atraque de las naves.

$2^{\circ}$. Lo mismo ocurre cuando se entorpece el uso del río, disminuyéndolo ya sea en el espacio o en el tiempo y esto acarrea consecuencias en la navegación o atraque de las naves.

$3^{\circ}$. Cualquier acto que traiga aparejadas las consecuencias referidas previamente, tales como la derivación de agua para fines de regadío o alimentación de un acueducto, el ensanchamiento o reducción del cauce, da lugar a la concesión del interdicto.

Como puede apreciarse no se trata de una actividad que simplemente consista en la derivación de agua del río, sino aquella de tal entidad que modifica la cantidad de agua, de tal modo que se traduce en un "incommudum", una "difficultas" o un total "impedimentum" del uso del río para los fines de la navegación.

Una confirmación respecto del presupuesto dañoso que permite la concesión del interdicto, aparece registrado en el siguiente texto:

D. 43, 13, 1, 3 (Ulp. 68 ad ed.)

Quod autem ait praetor 'aliter fluat', non ad quantitatem aquae fuentis pertinet, sed ad modum et ad rigorem cursus aquae referendus est.

Adicionalmente, Ulpiano nos da a conocer un testimonio que permite restringir las hipótesis a las que nos estamos refiriendo:

D. 43, 12, 1, 16 (Ulp. 68 ad ed.)

Labeo scribit non esse dandam exceptionem ei, qui interdicto convenitur: 'aut nisi ripae tuendae causa factum sit', sed ita excipiendum ait: 'extra quam si quid ita factum sit, uti de lege fieri licuit'. 
El problema se refiere a una obra realizada por un particular contra el que se dirige el interdicto, con el agregado de que dicha obra tiene por objetivo proteger la ribera del curso de agua, suponemos para evitar las consecuencias de un aumento explosivo del caudal. Nuestro jurista excluye que la defensa de las riberas pueda ser opuesta como eximente frente al interdicto pues el criterio que se aplica es el privilegiar la navegación, a menos que la actividad de refuerzo de las obras de contención fluvial hubiesen sido autorizadas por una lex ${ }^{136}$.

\section{INTERDICTO RESTITUTORIO}

El interdicto restitutorio, correlativo al de fluminibus imponía la obligación de volver las cosas al estado previo a la realización de las obras que hubieran ocasionado perjuicio a las condiciones de navegabilidad o posibilidades de atraque en el río público. El texto del mismo que nos da a conocer UlPiANO, es el siguiente:

\section{43, 12, 1, 19 (Ulp. 68 ad ed.)}

Deinde ait praetor: 'Quod in flumine publico ripave eius flat sive quid in id flumen ripamve eius immissum habes, quo statio iterve navigio deterior sit fiat, restituas'.

En lo que dice relación con el interés activo, la doctrina se pronuncia en términos generales por darle un carácter popular ${ }^{137}$, lo que parece ser razonable si se considera tanto el hecho de la finalidad del interdicto, como la circunstancia de que en su fórmula no aparece mención alguna a la persona del interesado ${ }^{138}$.

Otro asunto es lo que acontece con aquel contra el que se dirige este interdicto, pues de los datos suministrados por las fuentes, se puede concluir claramente, que el campo de aplicación es mucho más amplio que en el caso del prohibitorio:

\section{43, 12, 1, 21-22 (Ulp. 68 ad ed.)}

Iubetur autem is, qui factum vel immissum habet, restituere quod habet, si modo id quod habet stationem vel navigium deterius faciat. (22) Haec verba 'factum habes' vel 'immissum habes' ostendunt non eum teneri, qui fecit vel immisit, sed qui factum immissum habet, denique Labeo scribit, si auctor tuus aquam derivaverit, et hoc interdicto, si ea tu utaris.

El conminado a la realización de la restitutio, no es necesariamente quien realizó la obra de la que derivan los perjuicios, sino todos los que de una u otra forma mantienen las condiciones dañosas al momento de la concesión del interdicto. El criterio se ve reforzado por la alusión, nuevamente a LABEón, quien es de la opinión que el interdicto se extiende incluso a aquel que no ha realizado derivación alguna de agua desde el río público, pero que luego de adquirido el fundo donde finalmente esta agua es utilizada, también hace uso de ella.

En cuanto al contenido específico de la orden de restituir contenida en el interdicto, cuestión que tiene directa vinculación con la calificación que se hace respecto del comporta-

\footnotetext{
136 Fiorentini (2003) pp. 176-7.

137 Vid., por todos, Di Porto (1984) pp. 483 ss.

138 Alburquerque (2002) p. 279.
} 
miento de aquel contra el que va dirigido el interdicto, es útil recurrir a la discusión planteada respecto del significado del término "restituas" con relación al interdicto ne quid in itinere fiat, vinculado a obras que producen un empeoramiento en el tránsito de una vía pública:

\section{D.43, 8, 2, 43 (Ulp. 48 ad ed.)}

'Restituas' inquit. restituere videtur, qui in pristinum statum reducit: quod fit, sive quis tollit id quod factum est vel reponat quod sublatum est. et interdum suo sumptu: nam si ipse, quo qui interdixit, fecerit, vel iussu eius alius, aut ratum habitum sit quod fecit, ipse suis sumptibus debet restituere: si vero nihil horum intervenit, sed habet factum, tunc dicemus patientiam praestare debere.

El concepto es bastante amplio pues se limita señalar que "restituye el que vuelve las cosas a su estado anterior". Se complementa esta descripción argumentando que dicho objetivo se cumple: (a) reponiendo lo que se ha quitado; (b) sacando lo que se ha puesto.

Respecto de quién debe asumir el costo de las obras necesarias, el texto plantea dos posibilidadades: (a) que sea el mismo contra el que va dirigido el interdicto, en la medida que él hubiere realizado la obra dañosa; otro con su permiso o hubiere aprobado lo que un tercero hizo, y (b) que sea otro el que asuma el costo, lo que ocurre cuando no se han producido las situaciones anteriores y aquel contra el que se dirige el interdicto se ha limitado a retener lo que otro realizó. Indudablemente esta diferenciación nos hace evocar la situación vista a propósito de las consecuencias jurídicas del ejercicio de la actio aquae pluviae arcendae.

\section{INTERDICTUM NE QUID IN FLUMINE PUBLICO FIAT, QUO ALITER AQUA FLUAT, ATQUE UTI PRIORE AESTATE FLUXIT139}

Nuevamente nos encontramos, con un esquema de análisis que permite diferenciar entre un interdicto prohibitorio y otro restitutorio.

\section{INTERDICTO PROHIBITORIO}

El objeto de tutela en este interdicto, es distinta de aquella a que se refiere el caso analizado en la sección anterior, pues tiene que ver con la prohibición general para realizar obras tanto en el cauce del río como en sus orillas, que perjudiquen o impidan el normal flujo del agua, en las mismas condiciones en las que se producía en el verano anterior ${ }^{140}$ :

D. 43, 13, 1 pr. (Ulp. 68 ad ed.)

Ait praetor: 'In flumine publico inve ripa eius facere aut in id flumine ripamve eius immittere, quo aliter aqua fluat, quam priore aestate fluxit, veto'.

139 EP 43 \$242; Biscardi (1938) pp. 40 ss.; SCialoja (1928) pp. 224 ss.; Lauria (1932) pp. 243 ss.; Branca (1941) pp. 185 ss.; Albertario (1930) pp. 197 ss.; Longo (1966) pp. 52 ss.; Scherillo (1945) pp. 128 ss.; Di Porto (1990) pp. 104 ss.; Lazo (1999) pp. 72 ss.; Zoz (1999) pp. 154 ss.; Betancourt (2007) pp. 273 ss.

${ }^{140}$ Fiorentini (2003) p. 187; Palma (1989) pp. 120 ss. 
En relación a este interdicto, no existen dudas respecto de su aplicabilidad tanto respecto de los ríos navegables como en relación a los que no lo son ${ }^{141}$, pues específicamente UlPiANo se refiere a la situación en el siguiente texto:

\section{43, 13, 1, 2 (Ulp. 68 ad ed.)}

Pertinet autem ad flumina publica, sive navigabilia sunt sive non sunt.

La romanística no es uniforme en cuanto al contenido de este fragmento ${ }^{142}$, aun cuando nos inclinamos por su autenticidad, particularmente por el hecho de que la afirmación se realiza en términos absolutos, sin siquiera recurrir a la referencia a otro jurista, lo que de ocurrir podría darnos pistas respecto de una eventual discusión sobre el punto ${ }^{143}$.

En definitiva, la finalidad del interdicto se reduce a prohibir todos los actos que puedan ocasionar un perjuicio a aquellos que hacen uso del río, pero en la medida que dicho daño altere la corriente del mismo, evento dañoso que es descrito por Ulpiano con la expresión "aliter fluat"144:

\section{43, 13, 1, 1, (Ulp. 68 ad ed.)}

Hoc interdicto prospexit praetor, ne derivationibus minus concessis flumina excrescant vel mutatus alveus vicinis iniuriam aliquam adferat.

El texto está probablemente interpolado, pues se nota una falta de concordancia en su contenido ya que alude a dos posibles situaciones perjudiciales: (a) aumento del cauce del río, producido por derivaciones no autorizadas, o (b) daño causado a propósito del cambio del lecho del río. Específicamente en la primera de la hipótesis se da la inconsistencia que denunciábamos previamente pues una derivación de agua consiste en una sustracción de este elemento y por lo mismo, no se ve cómo ello podría redundar en un aumento del nivel de la corriente. Lo que parece ser una tesis coherente para tratar de entender el pasaje en cuestión, consiste en que él se refería originalmente a una acequia o conducto que lejos de derivar, introduce más agua en el cauce del río y produce un aumento en el nivel de la corriente $\mathrm{e}^{145}$.

En cuanto a la forma distinta en la que escurre el agua, Ulpiano indica que ella consiste en una modificación del "modus" o del "rigor" de la corriente del río, medido de acuerdo a como hemos dicho en relación al anterior verano y que además ocasiona perjuicios a los usuarios de dicho curso de agua ${ }^{146}$ :

\footnotetext{
${ }^{141}$ En el caso del interdicto prohibitorio de fluminibus, existe una controversia al respecto, surgida a propósito de la referencia a la opinión de Labeón en D. 43, 12, 1, 12 (Ulp. 68 ad ed.).

142 En contra de su autenticidad, Vid., Albertario (1930) pp. 303 ss.

143 Branca (1941) p. 178; Zoz (1999) p. 154; Alburquerque (2002) p. 292.

${ }^{144}$ D. 43, 13, 1 pr. (Ulp. 68 ad ed.).

145 Fiorentini (2003) p. 194.

146 Alburquerque (2002) p. 295.
} 
D. 43, 13, 1, 3 (Ulp. 68 ad ed.)

Ait praetor: 'quo aliter aqua fluat, quam priore aestate fluxit: non omnis ergo, qui immisit vel qui fecit, tenetur, sed qui faciendo vel immittendo efficit aliter, quam priore aestate fluxit, aquam fluere. quod autem ait 'aliter fluat', non ad quantitatem aquae fluentis pertinet, sed ad modum et id rigorem cursus aquae referendum est. et generaliter dicendum est ita demum interdicto quem teneri, si mutetur aquae cursus per hoc quod factum est, dum vel depressior vel artior fiat aqua ac per hoc rapidior fit cum incommodo accolentium: et si quod aliud vitii accolae ex facto eius qui convenitur sentient interdicto locus erit.

De las mismas palabras de Ulpiano, se entiende que el perjuicio es un cambio en el "cursus aquae" y no en la cantidad de agua ${ }^{147}$. Ahora, para poder establecer adecuadamente en qué consiste este perjuicio, vale la pena detenerse en el contenido del término "rigor", que es contextualizado a propósito de la definición de "orilla" atingente al régimen del interdicto de fluminibus $^{148}$ y que vincula el término en cuestión con los límites naturales o el curso normal de la corriente ${ }^{149}$. Otro tanto debemos hacer con la expresión "modus fluminis", especialmente porque hay que distinguirla nítidamente de la disminución de la cantidad de agua, situación inmersa en otra hipótesis y propia del interdicto de fluminibus. El asunto no es fácil, pues efectivamente uno de los posibles significados de "modus" permite llegar al criterio de la cantidad ${ }^{150}$, pero esta interpretación topa con la contraposición que UlPiAno realiza en el texto recién reproducido entre "quantitas aquae" y "modus cursus", lo que permite asegurar que en este caso la expresión en análisis tiene un sentido distinto al vinculado a la cantidad, identificable con las limitaciones impuestas a una determinada actividad y que podría entenderse como "el modo normal"151.

El perjuicio producido por el cambio de condiciones de escurrimiento del río, se identifica entonces con la disminución de la utilidad que dicho curso de agua representa para sus usuarios y, especialmente en el daño que se puede ocasionar a los predios ribereños, como ocurriría, por ejemplo con deslizamiento de una porción de terreno a causa de la erosión producida por la corriente del río, devenida en más impetuosa a causa de una obra efectuada en el álveo del mismo.

Un asunto relevante toca el ámbito de la oportunidad de ejercicio del interdicto, pues si esto ocurre durante el periodo de verano, debe tomarse como punto de comparación las condiciones del estío anterior, pero si se ejercita en invierno dicho punto será el del verano, pero no inmediatamente anterior, sino el previo a aquel.

\footnotetext{
147 Grosso (1941) pp. 124 ss., es el primero en acertar respecto de que el interdicto no busca proteger la cantidad o volumen de agua, pues esta finalidad se obtiene mediante el ejercicio del interdicto de fluminibus (D. 43, 12): el objetivo del interdicto que estamos comentando en este apartado, señala nuestro autor es tutelar el modo de escurrimiento del agua.

${ }^{148}$ D. 43, 12, 1, 5 (Ulp. 68 ad ed.): “...id, quod flumen continet naturalem rigorem cursus sui tenens...”.

149 Fiorentini (2003) p. 189.

${ }^{150}$ D. 18, 1, 51 (Paul. 21 ad ed.).

${ }^{151}$ Fiorentini (2003) p. 190. Esta tesis no carece de fundamento, especialmente si analizamos algunas fuentes extrajurídicas: Agenn. Urb., Contr. agr., 44, 5-9; 44. 15-20.
} 
En opinión de Alburquerque ${ }^{152}$, la permanente referencia de Ulpiano a los vecinos poseedores de los predios ribereños, no puede llegar a considerarse como una señal de restricción en cuanto al interés activo, pues si bien aquellos pueden ser los más perjudicados, esto no significa que otros también puedan verse lesionados por una actividad como la que supone la concesión del interdicto ${ }^{153}$. En esta misma línea se encuentra Fiorentini ${ }^{154}$, quien circunscribe este interdicto dentro de aquellos que reciben la denominación de "populares", precisamente por la amplitud en cuanto a los interesados activamente en él ${ }^{155}$. En todo caso y sin perjuicio de estar de acuerdo con los recientemente expuesto, es evidente que el interesado activamente, solo podía serlo en la medida que la situación lo afectara directamente, pues un perjuicio ocasionado de manera indirecta no era suficiente ${ }^{156}$.

Por último, para los partidarios de un interés activo restringido, el contenido del siguiente fragmento resulta un escollo difícil de poder soslayar, especialmente porque el contenido del mismo, no tiene aspectos que puedan dar cuenta de una eventual manipulación:

\section{43, 13, 1, 9 (Ulp. 68 ad ed.)}

Hoc interdictum cuivis ex populo competit, sed non adversus omnes, verum adversus eum, qui deneget, ut aliter aqua flueret, cum ius non haberet.

En el texto se afirma que la legitimación activa corresponde a cualquier persona y la pasiva contra el que realizó la obra que provoca que la corriente fluya de una forma diferente a la del estío anterior.

El interés pasivo recae no sobre las que han realizado una obra o introducido algo en el río público o su orilla, sino sobre los que realizando alguna de las acciones señaladas previamente han ocasionado que el agua fluya en condiciones distintas a las normales; o han generado un cambio en el cauce del río, especialmente en lo que se refiere a la velocidad de la corriente (D. 43, 13, 1, 3. Ulp. 68 ad ed.).

\section{43, 13, 1, 8 (Ulp. 68 ad ed.)}

Is autem hoc interdicto tenetur, qui aliter fecit fluere, quam priore aestate fluxit. et idcirco aiunt praetorem priorem aestatem comprehendisse, quia semper certior est naturalis cursus fluminum aestate potius quam hiene. nec ad instantem aestatem, sed ad priorem interdictum hoc refertur, quia illius aestatis fluxus indubitatior est.

También quedan sujetos al interdicto aquellos que pretendan modificar un curso de agua cubriéndolo si él escurre descubierto o descubriéndolo si lo hace cubierto ${ }^{157}$ :

\footnotetext{
152 Alburquerque (2002) pp. 293 ss.

${ }^{153}$ Zoz (1999) p. 155.

${ }^{154}$ Fiorentini (2003) p. 197.

155 Fiorentini, es de la idea de que el carácter público de este interdicto arranca de la naturaleza pública del río, la que de alguna manera se comunicaría al medio de tutela. No estamos de acuerdo con la tesis recién planteada pues ella no se condice con los principios en torno a los cuales operaban los juristas y porque además. ${ }^{156}$ Scherillo (1945) p. 128; Branca (1941) p. 179.

${ }^{157}$ Grosso (1941) p. 132.
} 
D. 43, 13, 1, 4 (Ulp. 68 ad ed.)

Si quis ex rivo tecto per apertum ducere velit contra qui ante aperto duxit nunc operto velit, interdicto teneri placuit, si modo hoc factum eius incommodum circa colentibus adferat.

Por último, es susceptible de solicitarse el interdicto contra el que condujera por un canal o acequia, o bien cambia su cauce:

D. 43, 13, 1, 5 (Ulp. 68 ad ed.)

Simili modo et si incile ducat au talio loco faciat aut si alveum fluminis mutet, hoc interdicto tenebitur.

Los fragmentos que analizaremos a continuación dan cuenta de la posibilidad de negar la concesión del interdicto. En ellos se indica reiteradamente que es posible oponer al ejercicio del mismo una exceptio, lo que nos motiva en pensar en una manipulación postclásica, toda vez que en el derecho clásico los interdictos no dan lugar a un juicio, que es precisamente la instancia donde se puede alegar una excepción. Sin perjuicio de lo anterior, no debemos descartar el análisis de las situaciones en las que nos pone UlPiAnO y que permiten discurso del texto, en el que se dan luces de una controversia jurisprudencial en torno al tema:

D. 43, 13, 1, 6-7 (Ulp. 68 ad ed.)

Sunt qui putent excipiendum hoc interdicto quod eius ripae muniendae causa non fiet, scilicet ut, si quid fiat, quo aliter aqua fluat, si tamen muniendae ripae causa fiat, interdicto locus non sit. sed nec hoc quibusdam placet: neque enim ripae cum incommodo accolentium muniendae sunt hoc tamen iure utimur, ut praetor ex causa aestimet, an hanc exceptionem dare debeat: plerumque enim utilitas suadet exceptionem istam dari. (7) Sed et si alia utilitas vertatur eius, qui quid in flumine publico fecit pone enim grande damnum flumen ei dari solitum, praedia eius depopulari, si forte aggeres vel quam aliam munitionem adhibuit, ut agrum suum tueretur eaque res cursum fuminis ad aliquid immutavit, cure i non consulatur? plerosque scio prorsus flumina avertisse alveosque mutasse, dum praediis suis consulunt. oportet enim huiusmodi rebus utilitatem ed tutelam facientis spectari, sine iniuria utique accolarum.

Podemos entender más adecuadamente los textos si los enfrentamos, tomando en consideración los siguientes aspectos, que permiten, a nuestro entender, desentrañar de forma más auténtica el sentido del largo fragmento recién reproducido:

$1^{\circ}$. Se manifiesta, sin darnos señas de quienes serían los protagonistas, la existencia de una controversia entre aquellos que admiten la posibilidad de no conceder el interdicto aunque la hipótesis descrita en su fórmula efectivamente se cumpla, cuando las obras realizadas en el río y que alteran su curso, fueron hechas para proteger la orilla.

$2^{\circ}$. Sin entrar en el detalle de las opiniones adoptadas por aquellos que se encuentran en una u otra posición, UlpiAno nos transmite el criterio del pretor: adhiriendo a 
la mayoría que está a favor de la tesis de la no concesión bajo las circunstancias descritas, el magistrado resuelve caso a caso ${ }^{158}$. En opinión de Longo ${ }^{159}$ y de AlburQUERQue ${ }^{160}$, es la idea de la "utilitas" la que lleva a admitir la posibilidad de negar la concesión del interdicto ${ }^{161}$, siempre que la acción haya sido realizada "sine iniuria utique accolarum".

$3^{\circ}$. Se presenta aquí un esquema en el que se exponen dos intereses contrapuestos: aquel del dominus del fundo que lo protege a través de obras realizadas en la orilla del río y que alteran las condiciones de escurrimiento del río y los de los accolentes, que sufren un perjuicio en virtud de esa obra.

40. En el $\$ 7$ se refiere una segunda hipótesis: se trata de un tipo de obra distinta de las anteriores y que se ha motivado por el hecho de que el río, suponemos por crecidas regulares, causa daño al predio del autor de las mismas. Como consecuencia de lo anterior, se realizaron obras de contención, que de algún modo alteraron el curso del río: Ulpiano es de la idea que aquí también se deben ponderar estas razones y por lo mismo, admitir la posibilidad de denegar el interdicto, particularmente por le hecho de que parece ser una situación bastante común en su época ${ }^{162}$.

En suma y en plena coincidencia con lo expuesto oportunísimamente por FioreNTI$\mathrm{NI}^{163}$, podemos decir que el argumento más significativo dentro de los pasajes que estamos analizando, “...consiste en la necesidad que se presenta de vincular las dos utilitates eventualmente en conflicto: aquella particular del titular del fundo ribereño y el interés general de la conservación del río, para la finalidad de preservar su uso general, que implica también la abstención de la manipulación del álveo...”.

\section{INTERDICTO RESTITUTORIO}

La fórmula del correlativo interdicto restitutorio aparece reproducida en el siguiente fragmento:

\section{43, 13, 1, 11 (Ulp. 68 ad ed.)}

Deinde ait praetor: 'Quod in flumine publico ripave eius factum sive quid in flumen ripamve eius immissum habes, si ob id aliter aqua fluit atque uti priore aestate fluxit, retituas'.

Se trata de una orden en la que se impone el restablecimiento del estado original respecto de lo que se haya realizado o introducido en un río público o en su orilla y que produjo la alteración del flujo natural del agua, cuyo punto de referencia está constituido

\footnotetext{
158 Fiorentini (2003) p. 200.

${ }^{159}$ LoNgo (1972) pp. 1 ss.

160 Alburquerque (2002) p. 297.

${ }^{161}$ La referencia a la excepción parece ser propia de una interpolación, pues en el derecho clásico los interdictos no motivan juicio alguno, situación que está reservada a las acciones.

162 Fiorentini (2003) p. 203.

163 Ibid., pp. 205 ss.
} 
por el estío anterior. Los mismos conceptos vertidos previamente respecto del interdicto prohibitorio se pueden considerar comprendidos para este caso ${ }^{164}$.

D. 43, 13, 1, 12-13 (Ulp. 68 ad ed.)

Hoc interdictum restitutorium proponitur superius enim probibitorium est et pertinet ad ea, quae nondum facta sunt. si quid igitur iam factum est, per hoc interdictum restituetur: si quid ne fiat prospicitur, superiore interdicto erit utendum et si quid post interdictum redditum fuerit factum, coercebitur. (13) In hoc interdicto restitutorium non est iniquum, ut Labeo ait, venire etiam, quod dolo factum est quo minus haberes.

De acuerdo a lo expuesto en el fragmento, lo que se pretende es la restitutio, la que no necesariamente debe ser realizada por el autor de la obra o de la immissio, sino que en definitiva esta se puede exigir al que retiene la obra, sea o no el autor de la misma ${ }^{165}$. Por último, y acogiendo la opinión de LABEón, se extiende la aplicación del interdicto en contra de quien ha dejado dolosamente de poseer lo hecho.

\section{INTERDICTUM UT IN FLUMINE PUBLICO NAVIGARE LICEAT 166}

La navegación fluvial se encontraba tutelada a través del interdicto a que nos referimos en este apartado, en forma de prohibición respecto del ejercicio de la violencia en orden a impedir dicha actividad o la de las vinculadas a labores de carga y descarga de mercancías, materializada en un río público o en sus orillas. Este mismo régimen luego se extiende a los lagos, presas o estanques ${ }^{167}$, en la medida que también tengan la categoría de públicos $^{168}$. La fórmula del interdicto a que nos referiremos en esta sección nos es conocida gracias al siguiente texto y para contextualizarlo adecuadamente, UlPiANo hace una analogía con aquellos que tutelan el uso de las vías públicas:

D. 43, 14, 1 pr.-1 (Ulp. 68 ad ed.)

Praetor ait: 'Quo minus illi in fumine publico navem ratem agere quove minus per ripam onerare exonerare liceat, vim fieri veto. item per lacum fossam stagnum publicum navigare liceat, interdicam'. (1) Hoc interdicto prospicitur, n equis flumine publico navigare prohibeatur: sicuti enim ei, quia via publica uti prohibeatur, interdicto supra propositum est, ita hoc quoque proponendum praetor putavit.

\footnotetext{
164 Alburquerque (2002) p. 297.

${ }^{165} \mathrm{Se}$ da en este caso, exactamente la misma situación que en D. 43, 12, 1, 22 (Ulp. 68 ad ed.).

166 EP $43 \$ 243$; Scialoja (1928) p. 224; Branca (1941) p. 159; Scherillo (1945) p. 126; Lazo (1999) p. 71; Zoz (1999), pp. 156 ss; Fiorentini (2003) pp. 182 ss.

167 El concepto de "lago"; "estanque" y "presa", son referidos en fragmentos sucesivos: D. 43, 14, 1, 3-5 (Ulp. $68 \mathrm{ad}$ ed.) y la posibilidad de que ellos sean públicos aparece específicamente mencionada en el $\$ 6$ del mismo fragmento.

${ }^{168}$ Fiorentini (2003) p. 182.
} 
Esta vinculación planteada por nuestro jurista nos remite necesariamente a dos tex$\operatorname{tos}^{169}$, uno contenido en D. 43, 8, 2, 20 (Ulp. 68 ad ed.) y otro en D. 43, 8, 2, 45 (Ulp. $68 \mathrm{ad}$ ed.) y en los que se consideran hipótesis que habilitarían para ejercer el interdicto de que tratan: (a) un hecho o acto del que deriva un empeoramiento de las condiciones del uso del camino, y (b) la realización de actos de violencia destinados a impedir el tránsito por una vía pública. Por cierto, que de estas dos situaciones, solo la segunda es la que pareciera tener en mente UlPiANo cuando presenta la analogía de los que nos estamos ocupando $^{170}$.

Un asunto llamativo se enfrenta cuando apreciamos que en el caso de este interdicto, se vuelve a la regla de tutelar los ríos públicos y navegables, pues esta categoría se contrapone a la de los cursos privados:

D. 43, 14, 1, 2 (Ulp. 68 ad ed.)

Si privata sunt supra scripta, interdictum cessat.

Pero al mismo tiempo, la aplicación del interdicto se extiende a hipótesis que indudablemente no pudieron estar consideradas originalmente, ya que distan mucho de tutelar la navegación o incluso las operaciones de carga y descarga. Un primer caso lo tenemos a propósito del siguiente texto:

D. 43, 14, 1, 7 (Ulp. 68 ad ed.)

Publicano plane, qui lacum vel stagnum conduxit, si piscari pribibeatur, utiler interdictum competeré Sabinus consentit: et ita Labeo. ergo et si a municipibus conductum habeat, aequissimum erit ob vectigalis favorem interdicto eum tueri.

Hay una ampliación de la tutela del interdicto, vía útil, radicando el interés activo en el publicano que arrienda un estanque o lago y se le impide pescar en ellos. Ya no se trata de proteger la navegación o su actividad conectada de carga o descarga, sino la pesca y como ha revelado D'ORS ${ }^{171}$, esta situación encontraría su explicación en el hecho de la especial naturaleza del arrendamiento a que se refiere el fragmento.

Otra aplicación por la vía de la extensión, nos permite conocer la opinión de MeLa, un jurista al que no hemos tenido previamente oportunidad de mencionar y que se pronuncia sobre la aplicación del interdicto a una hipótesis que se encuentra absolutamente alejada de su objetivo original:

\section{43, 14, 1, 8-9 (Ulp. 68 ad ed.)}

Si quis velit interdictum tale movere, ut locus deprimatur pecoris appellendi gratia, non debet audiri: et ita Mela scribit. (9) Idem ait tale interdictum competere, ne cui vis fiat, quo minus pecus ad flumen publicum ripamve fluminis publici appellatur.

\footnotetext{
${ }^{169}$ Fiorentini (2003) pp. 183 ss.

${ }^{170}$ Ibid., p. 184.

${ }^{171}$ D’Ors Lois (1976) p. 427.
} 
El orden lógico de los fragmentos pareciera estar invertido, pues en el $\$ 9$ se plantea la regla general, esto es que el interdicto se puede ejercer para proteger a aquel que lleva abrevar el ganado en un río público y que se ve impedido de aquello por el ejercicio de la violencia de un tercero. A su vez, en el $\$ 8$, se presenta la excepción a la regla general, porque se advierte que no se tutela la actividad que consiste en modificar el terreno del predio ribereño, aun cuando ello signifique un más fácil acceso para los animales, si consiste en rebajar el terreno de dicho predio ${ }^{172}$.

A diferencia de los interdictos anteriores, en este caso no existe un correlativo interdicto restitutorio, lo que permite conjeturar a Alburquerque ${ }^{173}$ la finalidad es la de evitar un daño futuro.

En cuanto a la legitimación popular al interdicto, la doctrina sigue discutiendo ${ }^{174}$ : Alburquerque ${ }^{175}$ y Lozano Corbi ${ }^{176}$ son de la opinión de que este interdicto tenía dicho carácter, pues si bien los textos parecen centrar su atención en el solicitante, como aquel que ha sufrido la violencia, al considerar las relaciones habidas con los interdictos que se refieren a las vías públicas, no parece ilógico pronunciarse en dicho sentido.

\section{INTERDICTUM DE RIPA MUNIENDA ${ }^{177}$}

La protección y reparación de las orillas de los ríos públicos presenta una utilidad que cae por su propio peso, dentro del contexto en el que estamos inmersos en este capítulo y ello es destacado por Ulpiano, quien nuevamente recurre al expediente de hacer una analogía con la tutela de las vías públicas ${ }^{178}$ :

D. 43, 15, 1, 1 (Ulp. 68 ad ed.)

Ripas fluminum publicorum reficere munire utilissimum est. sicuti igitur via publica reficienda interdictum propositum est, ita etiam de ripa fluminis munienda proponendum fuit.

Así, la fórmula del interdicto creado para los efectos antes anotados se concibe en los siguientes términos:

D. 43, 15, 1 pr. (Ulp. 68 ad ed.)

Praetor ait: 'Quo minus illi in flumine publico ripave eius opus facere ripae agrive qui circa ripam est tuendi causa liceat, dum neo b id navigatio deterior flat, si tibi damni infecti in

\footnotetext{
172 Alburquerque (2002) p. 306.

173 Alburquerque (2002) p. 302.

${ }^{174}$ Vid., por todos, Di Porto (1984) p. 511.

175 Alburquerque (2002) p. 303.

${ }^{176}$ LozANo (1982) p 189.

177 EP 43 \$244; Branca (1941) pp. 153 ss.; Longo (1966) p. 59; SCherillo (1945) p. 161; Lazo (1999) p. 73.

178 D. 43, 11, 1 pr. (Ulp. 68 ad ed.). Para Fiorentini (2003) p. 208; la analogía tiene mucho sentido en cuanto en ambos casos se protege la "utilitas publica".
} 
annos decem viri boni arbitratu vel cautum vel satisdatum est aut per illum non stat, quo minus viri boni arbitratu caveatur vel satisdetur, vin fieri veto'.

Es decir, se permite realizar todo tipo de obras con la finalidad de reparar las orillas de los ríos ${ }^{179}$, siempre que ellas no supongan un entorpecimiento a la navegación, criterio que es reiterado en el siguiente fragmento ${ }^{180}$ :

D. 43, 15, 1, 2 (Ulp. 68 ad ed.)

Merito adicit dum neo $b$ id navigio deterior fiat: illa enim sola refectio toleranda est. quae navigio non est impedimento.

Acumulados estos antecedentes, podemos concluir que el interdicto se puede ejercer en contra de todo aquel que impida por la vía de la fuerza, la realización de las reparaciones necesarias que garanticen la mantención en buen estado de las orillas ${ }^{181}$ de un río público o en un terreno próximo a ella. Sin perjuicio de lo ya anotado, el autor de las reparaciones u obras debe ser el poseedor o dominus de un fundo ribereño y no un tercero cualquiera, pues el texto edictal es claro en señalar que dichas obras debían tener como finalidad la de proteger a dicho fundo, lo que circunscribe la situación al dominus o poseedor de él, como hemos dicho, pues sería inexplicable que una persona distinta a estos tuviera el interés y la factibilidad de realizar estas acciones, especialmente si consideramos que para ello debería incurrir en una immissio sobre un predio ajeno ${ }^{182}$. Pero conjuntamente con este requisito de hecho, se debe unir la circunstancia de que el autor de estas obras otorgue garantía de reparar el daño temido ${ }^{183}$. Dicha garantía no se extendía sin límites en el tiempo, sino que se prolongaba por diez años:

D. 43, 15, 1, 3 (Ulp. 68 ad ed.)

Is autem, qui ripam vult munire, de damno futuro debet vel cavere vel satisdare secundum cualitate personae: et hoc interdicto expressum est, ut damni infecti in annos decem viri boni arbitratu vel caveatur vel satisdetur.

Recordemos que el sentido que debemos dar a la expresión "damno futuro", nos llega a través de un texto que reproduce la opinión de $\mathrm{GAYO}^{184}$, que lo concibe como aquel que todavía no se ha producido, pero que existen fundadas razones para temer que si llegue a ocurrir.

Vinculado con lo anterior, podría ser razonable la pregunta de si la garantía debe prestarse solo respecto de los vecinos a la orilla que se está reparando o también respecto

\footnotetext{
${ }^{179}$ Desde esta perspectiva tiene una finalidad absolutamente contraria a la que se atribuye al interdicto " $n e$ quid in flumine publico fiat, quo aliter aqua fluat, atque uti priore aestate fluxit".

${ }^{180}$ Dada esta característica, el interdicto solo se aplica a los ríos navegables.

181 Alburquerque (2002) p. 308.

182 Fiorentini (2003) p. 207.

183 Branca (1937) pp. 3 ss.; Betancourt (1975) pp. 8 ss.; Jiménez Salcedo (1999) pp. 216 ss.

${ }^{184}$ D. 39, 2, 2 (Gai. 27 ed. prov.).
} 
de los poseedores de la orilla contraria del río. Precisamente esto se resuelve en el siguiente texto:

D. 43, 15, 1, 4 (Ulp. 68 ad ed.)

Dabitur autem satis vicnis: sed et his, qui trans flumen possidebunt.

El análisis de estas fuentes nos lleva a representarnos la posibilidad de que el interdicto sea de aquellos que podríamos denominar "populares", en el sentido de concebir un interés activo para la generalidad de las personas. Somos contrarios a esta tesis especialmente por el hecho de que aquí parecen claramente determinados aquellos que cuentan con dicho interés: los que practiquen la navegación y los vicini de los fundos ribereños. Sobre estos presupuestos, tal como afirma Fiorentini ${ }^{185}$ es difícil admitir un interés a "quivis populo", como el que se da en el caso del interdicto "ne quid in flumine publico fiat, quo aliter aqua fluat, quam ut priore aestate fluxit".

La especial atención que se presta a todas estas circunstancias, encuentran su razón de ser en el hecho de que una vez que el perjuicio ya se ha ocasionado, no existe la posibilidad de recurrir al interdicto, debiendo buscarse protección jurídica a través de la actio legis Aquiliae ${ }^{186}$, como se encarga de indicar el texto que pasamos a reproducir:

D. 43, 15, 1, 5 (Ulp. 68 ad ed.)

Etenim curandum fuit, ut eis ante opus factum caveretur: nam post opus factum persequendi hoc interdicto nulla facultas superest, etiamsi quid dami postea datum fuerit, sed lege Aquilia experiendum est.

Por último, nada podemos decir respecto de la posible extensión del interdicto de ripa munienda, en relación con las orillas de lagos, presas o estanques públicos, como sí acontecía en el caso del interdicto analizado en el apartado anterior, aun cuando Ulpiano es de la opinión que por aplicación analógica sí debe considerarse esa posibilidad:

D. 43, 15, 1, 6 (Ulp. 68 ad ed.)

Illud notandum est, quod ripae lacus fossae stagni muniendi nihil praetor hic cavit: sed idem erit observandum, quod in ripa fluminis munienda.

\section{CONCLUSIONES}

$1^{a}$. Desde un punto de vista técnico, esto es la posibilidad de que una cosa sea reivindicada, el agua no es "res", puesto que no es susceptible el ejercicio de la acción reivindicatoria respecto de ella.

$2^{a}$. Incluso, mirado desde la perspectiva de las facultades del dominio, el agua no puede usarse, sino solo consumirse y no es objeto de posesión civil ni pretoria.

\footnotetext{
185 Fiorentini (2003) p. 210.

${ }^{186}$ Fiorentini (2003) p. 214.
} 
4a. Si nos remitimos exclusivamente a aquellos recursos que se relacionan directamente con el agua, nos encontramos con que estos son: la actio aquae pluviae arcendae, la vindicatio servitutis, la negatoria servitutis e interdictos. Ahora, si analizamos la finalidad seguida por cada uno de ellos, la verdad es que nos encontramos con un cuadro en el que lo que se tutela no es el agua sino la protección de un fundo respecto de eventuales daños o immissiones y el uso, admitido para todos, del recurso natural. Así, queda descartado el ejercicio de interdictos posesorios, como también de la acción Publiciana. El punto se remarca incluso si se piensa que el caso de un daño provocado al agua, el recurso que se debe deducir, de acuerdo a las fuentes, no es la actio legis Aquiliae, sino el interdicto quod vi aut clam.

5a. La tutela del agua, se hace especialmente a través de interdictos, y de ahí podemos concluir que el concepto que más se acerca al pensamiento de los juristas es que cualquiera se puede aprovechar del agua, mientras este provecho no perjudique a otros, afecte una servidumbre o signifique el ejercicio de hecho de una que no existe. $6^{a}$. Así, el interés de los juristas no es el de clasificar el agua dentro de las varias categorías de cosas, sino analizar el alcance y contenido de los interdictos que regulan su aprovechamiento.

7a. Desde la óptica previamente enunciada clasificar el agua como pública o privada, solo tiene sentido si se piensa que, en el primer caso, dicha calificación se sustenta en criterios similares a la que corresponde respecto de las calles, vías o murallas, pues respecto de estas cosas la República no ejerce dominium sino imperium. Por el contrario, si calificamos el agua como privada, ello solo puede entenderse bajo el prisma de la accesión de las mismas al predio por el que transcurren, entendida la accesión no como un modo de adquirir, sino en el sentido de formar parte de una cosa principal.

8a. De las fuentes que hemos revisado, queda en evidencia que la categoría de "público" o "privado", recae finalmente sobre los cursos de agua (flumina publicalflumina privata), pero no sobre el agua misma.

\section{BIBLIOGRAFÍA CITADA}

Albertario, Emilio (1930): "La derivazioni d'acqua dai fuimi pubblici in diritto romano", Bulletino dell'Istituto di Diritto Romano "Vittorio Scialoja” 38, pp. 197 ss.

Alburquerque, Juan Miguel (2002): La protección o defensa del uso colectivo de las cosas de dominio público. Especial referencia a los interdictos de publicis locis (loca, itinere, viae, flumina, ripae), (Dykinson, Madrid).

Astuti, Guido (1958): v. "acque”, Enciclopedia del Diritto 1, pp. 376 ss.

Betancourt, Fernando (1975): "Recursos supletorios a la cautio damni infecti”, Anuario de Historia del Derecho Español 35, pp. 8 ss.

Betancourt, Fernando (2007): Derecho Romano clásico (Sevilla, Universidad de Sevilla). BisCARDI, Arnaldo (1938): La protezione interdittale nel proceso romano (Padova, CEDAM). Birks, P.-Rodger, A.-Richardson, J.S. (1984): "Further aspects of the "tabula contebiensis"”, JRS 74, pp. 45 ss. 
Bonfante, Pietro (1922): "Il regime delle acque del diritto romano al diritto odierno", Archivio Giuridico 87, pp. 3 ss.

Bonfante, Pietro (1966): Corso di Diritto Romano. La proprietà (Milano, Dott. A. Giuffrè).

Branca, Giuseppe (1937): Danno temuto da cose inanimate nel diritto romano (Padova, CEDAM).

Branca, Giuseppe (1941): "Le cose "extra patrimonium humani iuris"”, Annali Triestini di Diritto, Economia e Politica 12, pp. 196 ss.

Brugi, Biagio (1894): "Studi sulla dottrina romana delle servitù prediali”, Archivio Giuridico 33. pp. 279 ss.

Burdese, Alberto (1957): v. "servitù prediali" (diritto romano), Novissimo Digesto Italiano, VII, pp 414 ss.

Capogrossi Colognesi, Luigi (1966): Ricerche sulla struttura delle servitù d'acqua in Diritto Romano (Milano, Dott. A. Giuffrè Editore).

Costa, Emilio (1918): Le acque nel diritto romano (Bologna, Incola Zanichelli).

De Martino, Francesco (1982): Diritto privato e società romana (Roma, Editore reuniti).

D’Ors LoIs, Javier (1976): “La “vis" en la tutela interdictal pública (A propósito de una hipótesis de Labruna), Persona y Derecho. Revista de fundamentación de las Instituciones Jurídicas, Vol. III, pp. 421 ss.

D’Ors Pérez-Peix, Alvaro (2004): Derecho Privado Romano, 10a edición revisada (Pamplona, EUNSA S.A.).

Di Porto, Andrea (1984): "Interdetti popolari e res in usu publico", Diritto e processo nella esperienza romana (Napoli, Jovene), pp. 483 ss.

Di Porto, Andrea (1990): La tutela della "salubritas" fra editto e giurisprudenza. Il ruolo di Labeone (Milano, Dott. A. Giuffrè Editore).

Gerez Kraemer, Gabriel (2008): El derecho de aguas en Roma (Madrid, Editorial Dykinson).

GLÜCK, Federico (1906): Commentario alle Pandette, continuazione del Prof. Ugo BurCKHARD, trad. Pietro Bonfante (Milano, Società Editrice Libraria).

Fiorentini, Mario (2003): Fiumi e Mari nell'esperienza giuridica romana.Profili di tutela processuale e di inquadramento sistematico (Milano, Dott. A. Giuffrè).

Gómez Royo, Enrique (1997): El régimen de las aguas en las relaciones de vecindad en Roma (Valencia, Tirant lo Blanch).

Grosso, Giuseppe (1941): Corso di Diritto Romano. Le cose (Torino, G. Giapichelli).

Grosso, Giuseppe (1969): Le servitù prediali nel diritto romano (Torino, G. Giappichelli).

Guzmán Brito, Alejandro (1996): Derecho Privado Romano, T. 1 (Santiago, Editorial Jurídica de Chile).

Jiménez Salcedo, María del Carmen (1999): El régimen jurídico de las relaciones de vecindad en Derecho Romano (Publicaciones de la Universidad de Córdova y Obra Social y Cultural Cajasur).

Karadge Iskrow, Nicolas (1928): Les choses publiques en Droit Romain (Paris, Peyronnet et Cie.).

Labruna, Luigi (1970): Vim fiero veto. A lle radici di una idelogia (Napoli, Jovene). 
Lauria, Mario (1932): "Le derivazione di acque pubbliche”, Annali Macerata 8, pp. 243 ss. LAzo, Patricio (1999): "El régimen jurídico de las aguas y la protección interdictal de los ríos públicos en el Derecho Romano", Revista de Estudios Histórico-Juridicos XXI, pp. 65 ss.

Longo, Giannetto (1966): "Il regime delle concesión e le derivazioni di acque pubbliche nel diritto romano classico e giustinianeo", Ricerche Romanistiche, pp. 177 ss.

Longo, Giannetto (1972): ““Utilitas publica””, Labeo 18, pp. 7 ss.

Lozano Corbí, Enrique (1982): La legitimación popular en el proceso romano clásico (Bosch, Barcelona).

Mantello, A. (2001): "De Iurisconsultorum Philosophia. Spunti e riflessioni sulla giurisprudenza dell primo Principato", Studia et Documenta Historiae et Iuris 62, pp. 3 ss.

Martini, Remo (1966): Le definizioni dei giuristi romano (Milano, Dott. A. Giuffrè).

Ossig, Alfred (1898): Römisches Wasserrencht (Leipzig, Von Duncker).

Palma, Antonio (1989): "Iura vicinitatis". Solidarietà e limitazioni nel rapporto di vicinato in diritto romano dell'età classica (Torino, G. Giapichelli).

Plescia, Joseph (1993): “The Roman Law on waters", Index 21, pp. 433 ss.

Rовве, Ubaldo (1979): La differenza sostanziale fra res nullius e res nullius in bonis e la distinzione dell res pseudo-marcianea (Milano, Serie Pubblicazioni dell'Istituto di Scienze Giuridiche, Economiche, Politiche e Sociali della Università di Messina).

Rodger, Alan (1989): "Position of aquae ductus in the Praetor's Edict", New Perspectivs in the Roman Law of Property, pp. 177 ss.

Rouge, J. (1966): Recerches sur l'organisation du commerce maritime en Méditerranée sous l'Empire Romain (París, Sevpen).

SARgenti, Manlio (1965): "Il regime dell'alveo derelitto nelle fonti romane", Bulletino dell'Istituto di Diritto Romano "Vittorio Scialoja" 58, pp. 265 ss.

Scherillo, Gaetano (1945): Lezioni di diritto romano. Le cose. Parte prima. Concetto di cosa. Cose extra patrimonium (Milano, A. Giuffrè).

Scialoja, Vittorio (1928): Teoria della proprietà nel diritto romano, Vol. I (Roma, Edita Pietro Bonfante).

SEGRè, Gino (1941): Le cose, la proprietà e gli altri diritti reali. Corso di diritto romano (Torino, G. Giappichelli).

Torrent, Armando (1982-1991): "El origen de la servitus aquaeductus a la luz de la Tabula Contrebiensis", Studi in onore di Arnaldo Biscardi, II (Milano, Istituto Editoriale Cisalpino La Goliardina), pp. 261 ss.

Unterholzner, K.A.D. (1840): Quellenmäbige Zusammenstellung der Lehre des Römischen Rechts Von Den Schuldverhältnissen (Leipzig).

VAsalli, Filippo (1939): "Premesse sotoriche all'interpretazione della nouva legge sulla acque pubbliche", Studi Giuridici II (Roma, Foro Italiano), pp. 37 ss.

Zoz, Maria Gabriela (1999): Riflessioni in tema di res publicae (Torino, G. Giappichelli). 